\title{
1 Seasonal snow cover regime and historical 2 change in central Asia from 1986 to 2008
}

3 Hang ZHOU ${ }^{1}$, Elena AIZEN ${ }^{1}$, Vladimir AIZEN ${ }^{1}$

$4{ }^{1}$ Geography Department, College of Science, University of Idaho, Moscow ID 83844, U.S.A.

5 E-mail: hzhou@uidaho.edu

6 Phone: 1-208-392-2829 
8 Abstract

9 A series of statistics describing seasonal snow cover extent and timing in Central Asia (CA) have

10 been derived from AVHRR satellite images for the time period from 1986 to 2008. Analysis of

11 long term mean snow cover statistics shows that the area weighted mean of long term snow

12 covering days (SCD) for the whole $\mathrm{CA}$ is $95.2 \pm 65.7$ days. High elevation mountainous areas

13 above $3000 \mathrm{~m}$ in Altai, Tien Shan and Pamir, which account for about $2.8 \%$ of total area in CA,

14 have SCD greater than 240 days. Deserts (Karakorum Desert, Taklamakan Desert, Kumtag

15 Desert) and rain shadow areas of major mountains, accounting for $27.0 \%$ of total area in CA,

16 have SCD in the range of 0 - 30 days.

17 Factors affecting snow cover distribution have been analyzed using simple linear regression and

18 segmented regression. For plain regions and windward regions, the SCD rate is +5.9 days / 100

$19 \mathrm{~m}$, while for leeward regions, the rate jumps from +0.7 days $/ 100 \mathrm{~m}$ to +10.0 days $/ 100 \mathrm{~m}$ at

20 about $2335 \mathrm{~m}$. Latitude affects the SCD, especially in plain regions with insignificant change of

21 elevation, with rates of 9 - 10 days / degree from south to north.

22 The Mann-Kendal test and the Theil-Sen regression methods have been applied to analyze the

23 spatial heterogeneous trends of change of SCD, snow cover onset date (SCOD), and snow cover

24 melt date (SCMD). Area weighed mean SCD in the whole CA does not exhibit significant trend

25 of change from 1986 to 2008. Increase of SCD was observed in the northeastern Kazakh Steppe.

26 Low elevation areas below $2000 \mathrm{~m}$ in Central Tien Shan and Eastern Tien Shan, as well as mid-

27 elevation areas from $1000 \mathrm{~m}$ to $3000 \mathrm{~m}$ in Western Tien Shan, Pamiro-Alai and Western Pamir,

28 also experienced increase of SCD, associated with both earlier SCOD and later SCMD. Decrease 
29 of SCD was observed in mountainous areas of Altai, Tien Shan and Pamir, and vast areas in

30 plains surrounding the

Aral Sea. 


\section{Introduction}

32 Seasonal snow cover is an important component of the hydrological cycle, affecting glacier mass

33 balance (Jansson et al., 2003), soil moisture content (Edwards et al., 2007) and river runoff

34 (Dozier, 1987; Singh, 2010). In many arid or semi-arid regions, seasonal snow cover is the major

35 water resource for both natural ecosystems and human society (Barnett et al., 2005). In central Asia

$36\left(\mathrm{CA}^{1}\right)$, melt water from seasonal snow cover is the dominant component of river runoff, as pointed

37 out by various researches of selected river basins (Aizen et al., 1995; 1996; Chevallier et al., 2014;

38 Pohl et al., 2014) or general estimation for the large regions (Barnett et al., 2005).

39 Seasonal snow cover has also been considered as an essential climate variable, as its varying extent,

40 depth, and surface properties have impacts on the surface energy balance and atmosphere circulation

41 (Li et al., 2014; Handorf et al., 2015), via its modification of surface albedo (Robinson et al., 1986;

42 Chapin et al. 2005) and the energy consumption during the snow melting phase (Aizen et al., 2000).

43 Seasonal snow cover is sensitive to the changing climate, as numerous studies report a decrease of

44 seasonal snow cover in northern hemisphere since the 1970s due to increasing air temperature

45 (Groisman et al., 1994; Dye, 2002; Choi et al., 2010; Peng et al., 2013). CA has experienced a

46 general increase of temperature in the $20^{\text {th }}$ century (Aizen et al., 1997; Lioubimtseva et al., 2005;

47 Aizen et al., in preparation), while climate models predicted a further warming up to $7{ }^{\circ} \mathrm{C}$ until the

48 end of the 21st century (Mannig et al., 2013; IPCC, 2014). Possible decrease of seasonal snow

49 cover extent in the high mountains of Tien Shan and Pamir, and the associated decrease of river

\footnotetext{
${ }^{1}$ List of abbreviations

CA: Central Asia; CARs: Central Asian Republics; KS: Kazakh Steppe; AD: Aral-Caspian Desert; TR: Tarim; SA:

Siberian Altai-Sayan; MA: Mongolian Altai; WT: Western Tien Shan; NT: Northern Tien Shan; IK: Issyk Kul; IT: Inner Tien Shan; ET: Eastern Tien Shan; CT: Central Tien Shan; WP: Western Pamir; PA: Pamiro-Alai; CP: Central Pamir EP: Eastern Pamir; SCE: Snow Cover Extent; CDR: Climate Data Record; SCAP: Snow Cover Area Percentage;

PSCAP: Perennial Snow Cover Area Percentage; SCD: Snow Covering Days; SCOD: Snow Cover Onset Date; SCMD: Snow Cover Melt Date; SCmax: Maximum Snow Cover Area Percentage; DSCmax: Date of Maximum Snow Cover Area Percentage
} 
runoff are the major consequences of climate change in CA (Ososkova et al., 2000; Siegfried et al.,

51 2012).

52 Various efforts have been spent on studying seasonal snow cover in CA, dating back to the time of

53 the former Soviet Union (FSU). From a current perspective, those studies are outdated by using only

54 data before the 1990s (Kotlyakov et al., 1997; Aizen et al., 1997), or working on the whole

55 northern hemisphere using coarse resolution satellite images or in-situ observations (Groisman et

56 al., 1994; Brown, 2000; Dye, 2002; Brown \& Robinson, 2011), or focusing on sub-regions within

57 CA using recent satellite images or station observations (Liang et al., 2008; Wang et al., 2008;

Zhou et al., 2013; Wang et al., 2013; Dietz et al., 2014). Our previous work (Zhou et al., 2013)

constructed a long term historical archive of snow cover extent data using AVHRR satellite images

60 from 1986 to 2008 for the whole CA, and analyzed the patterns of snow cover change in the Amu

61 Dar'ya Basin. The results showed a significant decrease of Snow Covering Days (SCD) in

62 mountainous regions above $3000 \mathrm{~m}$ in the basin, mainly accompanied by earlier Snow Cover

63 Melting Date (SCMD), while Snow Cover Onset Date (SCOD) shifted earlier in mid-elevation zone

64 (2000 - $3000 \mathrm{~m})$ of Western Pamir. Dietz et al. (2014) analyzed snow cover changes from 1986 to

652014 using AVHRR data within the country boundaries of Central Asian Republics (CARs),

66 Kazakhstan, Kyrgyzstan, Tajikistan, Turkmenistan and Uzbekistan, showing that SCMD shifted

67 earlier significantly in elevation zone between $2100 \mathrm{~m}$ and $3500 \mathrm{~m}$, while SCOD moved earlier over

68 the CARs and no significant change of SCD was detected in any elevation zone. There exists a

69 knowledge gap after Kotlyakov et al. (1997) about the seasonal snow cover regime for the whole

70 CA based on recent comprehensive remote sensing dataset. The slight difference between the two

71 recent studies about snow cover changes in CA also suggest that the analysis of the seasonal snow

72 cover change in a finer spatial resolution than before is needed to better understand the spatial

73 heterogeneous changes of seasonal snow cover after the late 1980s. 
74 In this study we analyzed a series of snow cover statistics derived from the AVHRR snow cover

75 extent data archive for the whole CA geographical region to quantify: 1) the spatial distribution and

76 timing characteristics of seasonal snow cover duration, 2) the determining factors for seasonal snow

77 cover distribution, including elevation, relative location to major mountain systems, and latitude, 3)

78 the changing patterns of seasonal snow cover for the research period from 1986 to 2008 and, 4) the

79 relationship between changes of seasonal snow cover and climate.

\section{Research Area}

81 In this study CA is defined as the geographical region in the center of the Eurasian continent,

82 spanning from $51^{\circ} \mathrm{E}$ to $113^{\circ} \mathrm{E}$, and from $32^{\circ} \mathrm{N}$ to $56^{\circ} \mathrm{N}$ (Figure 1). The Mongolian Steppe and the

83 Gobbi Desert are located in its east, while the Caspian Sea and the Aral Sea are situated in the west.

84 Western Siberia and the Altai-Sayan Mountains are located in the north, while the Taklamakan

85 Desert and the Karakum Desert are situated in the south. The CA region, as considered in this study,

86 covers an area of $\sim 6.3 \times 10^{6} \mathrm{~km}^{2}$, including the entire territory of CARs, as well as Xinjiang

87 Autonomous Region in China and southwestern Siberia in Russia.

88 Though the major terrain type within CA is plains (Figure 1), the major mountain ranges of CA

89 extend for more than $5000 \mathrm{~km}$, from the Altai Mountains in the north (Figure 1-A) to the Pamir

90 Mountains in the south (Figure 1-C), with the Tien Shan Mountains situated between these two

91 mountain systems (Figure 1-B). High mountains in CA modulate the air mass movement and

92 control moisture distribution and atmospheric pressure in low to mid latitude of Asia. Various

93 studies have pointed out that the westerlies is the dominant wind in CA, bringing moisture to this

94 region from the Atlantic Ocean (Aizen et al., 2004; Aizen et al., 2005; Aizen et al., 2009; Mölg et

95 al., 2013). The high mountains also serve as 'water towers' (Barnet et al., 2005; Immerzeel et al., 96 2010). 
97 To estimate the spatial variability of seasonal snow cover and its changing patterns, we further

98 subdivide CA into 15 climatic regions (Figure 1), according to certain climatic considerations and

99 topographical features (Aizen et al., in preparation).

\section{Data and methods}

\section{$101 \quad 3.1$ Snow cover statistics}

102 Snow cover extent data derived from Advanced Very High Resolution Radiometer (AVHRR) were

103 used as the basis for calculating snow cover statistics in this research. All AVHRR level-1b data

104 available for CA (NOAA, 1998; NOAA, 2007) were collected and processed with Special AVHRR

105 Processing Software (SAPS) (Khlopenkov et al., 2007) for calibration and georectification. An

106 aggregated rating based snow identification scheme was used to generate daily AVHRR snow cover

107 extent, which was further composited into 8-day maximum-snow-extent data. The 8-day maximum-

108 snow-extent data went through a set of spatial and temporal filters for filling cloudy pixels or gaps

109 (Zhou et al., 2013). A series of snow cover statistics were calculated from the $1 \mathrm{~km}$ resolution 8-day

110 AVHRR Cloud/Gap Free Maximum Snow Extent data.

111 We performed extensive validations of the AVHRR snow cover products at different processing

112 levels and different temporal resolutions to ensure the trustworthiness of the data. To ensure

113 temporal stability of the snow cover identification scheme, snow cover data derived from AVHRR

114 image segments obtained by different satellites at the same day were compared. The results show

115 that the general accuracy between different AVHRR sensors is always higher than $90 \%$. Daily

116 AVHRR snow cover data were compared with in-situ ground snow survey (Figure 1) in 1987 -

1171996 (Krenke, 1998). Due to the recoding constraint of the snow survey data, we only analyzed the

118 Probability of Detection (POD) of snow identification. Annual average POD is within the range of

$11980 \%-93 \%$, with a mean of $88.18 \%$. Furthermore, daily AVHRR snow cover products were 
120 compared with daily MODIS snow cover products in $2003-2008$. Both snow cover products

121 perform similarly with a general accuracy of $98.51 \%$ and a kappa coefficient of 0.89 . More details

122 about the accuracy of the snow cover products utilized in this study can be found in (Zhou et al.,

123 2013).

124 3.1.1 Snow Cover Area Percentage (SCAP) and Perennial Snow Cover Area Percentage

125 (PSCAP)

126 The 8-day Cloud/Gap Free Maximum Snow Extent data at $1 \mathrm{~km}$ resolution was synthesized into 5

$127 \mathrm{~km}$ resolution SCAP (\%) data by calculating the percentage of snow covered area within the $5 \mathrm{~km}$

128 grid, for representing the variation of snow cover in CA. Then PSCAP (\%) was computed as the

129 minimum value of SCAP at each $5 \mathrm{~km}$ grid point in all 8-day periods from 1986 to 2008 to represent

130 the spatial distribution of perennial snow and glaciers.

\section{$131 \quad$ 3.1.2 Snow Covering Days (SCD)}

132 SCD (days) is defined as the number of days covered by snow in a hydrological year for a grid point.

133 The start of a hydrological year in CA is defined as August $29^{\text {th }}$, which is the start of $31^{\text {st }} 8$-day

134 period, based on analysis of long-term meteorological and hydrological data in the research region.

$135 \mathrm{SCD}$ was first calculated at $1 \mathrm{~km}$ resolution then synthesized to $5 \mathrm{~km}$ resolution with the mean 136 function.

137 3.1.3 Snow Cover Onset Date (SCOD) and Snow Cover Melt Date (SCMD)

138 SCOD (Julian day) and SCMD (Julian day) were calculated as the start and end dates of stable snow

139 duration in a hydrological year at each $1 \mathrm{~km}$ grid point for describing the timing of seasonal snow

140 cover using an approximation algorithm (Wang et al., 2009; Zhou et al., 2013). Both SCOD and

141 SCMD for each hydrological year calculated at $1 \mathrm{~km}$ resolution were then synthesized to $5 \mathrm{~km}$

142 resolution by the mean function. 
143 SCOD is calculated by the following equation:

$144 \mathrm{SCOD}=\mathrm{D}^{\prime}-\mathrm{SCD}$,

Eq. 1

145 where SCD' is the number of days with snow cover within the period of snow starting season, which

146 was determined by the climate regime of our research region, while $\mathrm{D}^{\prime}$ is the Julian day of the end of

147 the defined snow starting season.

148 Similarly, SCMD is calculated as:

$149 \mathrm{SCMD}=\mathrm{D} "+\mathrm{SCD}$, Eq. 2

150 where SCD" is the number of days covered by snow within the period of snow melting season, and

151 D" is the Julian day of the start of the defined snow melting season.

152 Based on analysis of long term meteorological and hydrological data in the research region, the 153 snow starting season is defined as from the start of a hydrological year, which is August $29^{\text {th }}$ (the 154 start of the $31^{\text {st }} 8$-day period in a year) to December $27^{\text {th }}$ (the start of the $46^{\text {th }} 8$-day period in a year).

155 The snow-melting season is defined as the period from January $17^{\text {th }}$ (the start of the $3^{\text {rd }} 8$-day period 156 in a year) to the May $1^{\text {st }}$ (the start of the $16^{\text {th }} 8$-day period in a year) for our study region $(\mathbf{Z H O U}$, et 157 al., 2013).

158 3.1.4 Maximum Snow Cover Area Percentage (SCmax) and Date of Maximum Snow Cover 159 Area Percentage (DSCmax)

160 SCmax (\%) and DSCmax (Julian day) were derived from SCAP data at $5 \mathrm{~km}$ resolution, with 161 SCmax defined as the maximum SCAP at each grid point in a hydrological year, and DSCmax as 162 the corresponding date when SCmax was observed. 


\section{$163 \quad$ 3.1.5 Long term mean snow cover statistics}

164 Long term mean values, as well as standard deviations of SCAP, SCD, SCOD, SCMD, SCmax and 165 DSCmax were calculated to represent the general distribution of seasonal snow cover in CA from 1661986 to 2008.

167 Simple linear regression and segmented regression (Muggeo et al., 2008) with five different types 168 of model formulations (Table 2-1) were conducted in the R software (R Core Team, 2015) to 169 analyze the dependence of long-term mean SCD $(S C D)$ on elevation and latitude in different

170 climatic regions. Comparisons of the performance of these models for each climatic region were

171 conducted based on adjusted $\mathrm{R}^{2}$, AIC and ANOVA test with significance level at 0.05 . Comparisons

172 among the 'Only latitude', 'Only elevation' and 'Elevation and latitude' models show relative

173 importance of elevation and latitude on $S C D$ in different climatic regions. Comparison between

174 'Only elevation' and 'Breaking elevation', and comparison between 'Elevation and latitude' and

175 'Breaking elevation and latitude' examine and analyze the existence of segmented linear

176 relationship between $S C D$ and elevation.

\section{$177 \quad 3.2$ Trend of change analysis}

178 Both linear trend test and Mann-Kendall test (Mann, 1945; Kendal, 1975) were performed on time

179 series of SCD, SCOD, SCMD, SCmax and DSCmax with a significance level of 0.05 for detecting 180 possible trend of change of snow cover statistics. The slopes calculated by the Theil-Sen regression

181 (Theil, 1950; Sen, 1968; Fernandes et al., 2005) were reported as indicators of the general

182 direction and magnitude of change, for grid points where both tests show a same sign of change and 183 have p-values less than 0.05 . 
184 Hierarchical Clustering (Lattin et al., 2003) analysis was applied at each climatic region for each

185 trend slope calculated to group clustering points with same direction and similar magnitude of 186 change together. Location (standardized projected $\mathrm{x}$ and y coordinates in meters) and magnitudes of

187 significant trend of change were used as input variables. For each cluster, the mean and standard

188 deviation of magnitudes of change were reported.

\section{$189 \quad 3.3$ Auxiliary data}

190 The Digital Elevation Model (DEM) obtained from the Consultative Group on International 191 Agricultural Research (CGIAR) (Reuter et al., 2007) was used to describe topography in CA. The 192 DEM at $90 \mathrm{~m}$ resolution has been re-projected to the same coordinate system (Zhou et al., 2013) as 193 the snow cover statistics data, and resampled to $5 \mathrm{~km}$ resolution.

194 Gridded monthly air temperature and precipitation dataset derived from an archive of 457 stations in

195 CA was used in this study to provide a general overview of climate change during the research

196 period in CA (Aizen et al., in preparation). Regional averaged values of air temperature and 197 precipitation were calculated in defined latitudinal and longitudinal ranges, corresponding to groups 198 of regions (Table 1) in Aral Sea, Altai, northeastern Kazakh Steppe, Pamir and different parts of 199 Tien Shan.

\section{Results}

\section{$201 \quad$ 4.1 Spatial distribution of seasonal snow cover}

202 Long-term mean snow covering days ( $S C D$ ) (Figure 2-b) was used as the main seasonal snow

203 cover characteristic, since the long-term mean snow cover onset date (SCOD) (Figure 2-c) and the

204 long-term mean snow cover melt date $(S C M D)$ (Figure 2-d) have similar spatial distribution 
205 patterns as $S C D$. The whole CA has an area weighted mean of 95.2 days for $S C D$ with a standard

206 deviation of 65.7 days, while the area weighted mean values of SCOD and SCMD are Nov $23^{\text {rd }} \pm$

20726 days and Mar $7^{\text {th }} \pm 36$ days, respectively. Analysis of these snow cover characteristics (Figure 1,

208 Figure 2-b, 2-c and 2-d) shows that mountainous areas of Altai (> $2000 \mathrm{~m})$, Tien Shan (> $3000 \mathrm{~m})$

209 and Pamir (> $3000 \mathrm{~m}$ ), accounting for $2.8 \%$ of total area in CA, experience the highest $S C D$, which

210 is greater than 240 days. Those mountainous areas also have the highest perennial snow cover area

211 percentage (PSCAP) (Figure 2-a). Vast areas in northern CA, spanning from the Kazakh Steppe to

212 the low elevation areas $(<2000 \mathrm{~m})$ in Siberian Altai, have $S C D$ in the range of $90-240$ days; while

213 southern CA with elevation lower than $3000 \mathrm{~m}$, spanning from Aral-Caspian to Tarim, have $S C D$ in

214 the range of $0-90$ days. Areas with low values of SCD (0 - 30 days), accounting for $27.0 \%$ of total

215 area in CA, mainly distribute in deserts, including the Karakorum Desert spanning from Aral-

216 Caspian to southeastern part of Western Pamir, the Taklamakan Desert in Tarim, and the

217 Kumtag Desert at the southeastern part of Eastern Tien Shan. Low values of SCD below 30 days

218 can also be observed in rain shadows of great mountains, such as the western coast of Lake Issyk

219 Kul and the southeastern part of Inner Tien Shan (Figure 2-b).

220 More than $73 \%$ of the areas in CA have long-term mean maximum snow cover (SCmax) higher

221 than $95 \%$. Two main areas with SCmax less than $95 \%$ are the Karakorum Desert and the

222 Taklamakan-Kumtag deserts spanning from Tarim to southeastern part of Eastern Tien Shan

223 (Figure 2-e). The long-term mean date of maximum snow cover (DSCmax) is observed after Jan $1^{\text {st }}$

224 in most areas in CA. High mountains in Pamir, Tien Shan and Altai have earlier DSCmax before 
225 Jan $5^{\text {th }}$, compared with vast areas with low elevation $(<3000 \mathrm{~m})$, which have DSCmax between Jan

$2265^{\text {th }}$ and Jan $26^{\text {th }}$ (Figure 2-f).

\section{$227 \quad$ 4.2.1 Plains}

228 Kazakh Steppe (KS) has an average $S C D$ of $124.5 \pm 32.6$ days. The $S C D$ increases with latitude,

229 from about $91.6 \pm 24.9$ days in the south to $139.8 \pm 16.1$ days in the north. At maximum, $83.6 \%$ of

230 KS area is covered by snow on the $1^{\text {st }}$ day of year (Figure 3-1). The snow coverage stays above

$23180 \%$ until approximately the $50^{\text {th }}$ day of year (Feb 19), drops down quickly to below $1 \%$ on the $110^{\text {th }}$

232 day of year (Apr 20), then starts building up on approximately the $270^{\text {th }}$ day of year (Sept 27).

233 Aral-Caspian Desert (AD) has a short area weighted mean of $S C D(36.2 \pm 27.5$ days). The

234 shortest $S C D$ (0 - 5 days) can be observed in its southwestern part along the seashore of the Caspian

235 Sea, and in its southeastern part in the Karakum Desert. Longer $S C D(108.1 \pm 29.7$ days $)$ is

236 observed along the Kopet Dag Mountains at the southern border of AD with the Iranian Plateau.

237 Except for those local cases, the $S C D$ shows an increasing trend along latitude, from about $10.6 \pm$

2387.0 days at its southern part to about $54.0 \pm 18.4$ days in its northern part. The maximum snow area

239 coverage of $45.3 \%$ is observed on the $1^{\text {st }}$ day of year (Figure 3-2). The snow cover shrinks quickly

240 to below $0.01 \%$ on the $100^{\text {th }}$ day of year (Apr 10), leaving only the Kopet Dag Mountains hosting

241 remaining snow cover. After about the $300^{\text {th }}$ day of year (Oct 27), snow cover starts building up.

\section{$242 \quad 4.2 .2$ Altai and surrounding areas}

243 Siberian Altai-Sayan (SA) has a longer area weighted mean of $S C D(172.1 \pm 47.5$ days) than its

244 southeastern neighbor Mongolian Altai (MA) (101.3 \pm 53.2 days), because SA receives more

245 moisture from the westerlies due to its northwest location to the Altai Mountains. High mountains (> 
$2463000 \mathrm{~m})$ facing north or west in SA have a long SCD (294.0 \pm 31.8 days). Low elevation areas,

247 when surrounded by high mountains, have a mean $S C D$ of $123.1 \pm 24.8$ days, in contrast with the

248 longer mean $S C D$ of $166.3 \pm 19.0$ days when in open environment. The maximum snow cover is

249 observed at the end of a calendar year at about 75.0\% (Figure 3-4). The snow coverage stays above

$25060 \%$ to around the $100^{\text {th }}$ day of year (Apr 10), then goes down to below $1 \%$ on about the $170^{\text {th }}$ day

251 of year (Jun 19), while the snow cover expansion starts around the $220^{\text {th }}$ day of year (Aug 8).

252 MA also has long $S C D$ in mountains with a mean value of $225.6 \pm 45.7$ days, though shorter than in

253 the mountains of SA. The western Mongolia part of this climatic region experiences even shorter

$254 S C D(63.6 \pm 21.8$ days $)$ compared with the southern part of this climatic region (103 \pm 18.7 days),

255 since it is surrounded by the Eastern Sayan Mountains in the north, the Mongolian Altai Mountains

256 in the south, the Siberian Altai Mountains in the west and the Mongolian Plateau in the east. The

257 snow coverage in MA reaches its maximum of 69.9\% at the beginning of a calendar year (Figure 3-

258 5), shrinks down to around $2 \%$ on the $160^{\text {th }}$ day of year (Jun 9), and then starts expanding on around 259 the $250^{\text {th }}$ day of year (Sep 7).

\section{$260 \quad$ 4.2.3 Tien Shan and surrounding areas}

261 Western Tien Shan (WT) has a short mean SCD (80.2 \pm 67.8 days) mainly because of the

262 existence of a large area of warm and dry plains in its western part with low values of SCD (37.6 \pm

263 18.1 days), including the Fergana Valley. The mountainous areas in the northeastern part of WT

264 have longer $S C D(227.6 \pm 63.8$ days $)$. In WT, the maximum snow cover of $58.8 \%$ of the total area

265 is observed on the $9^{\text {th }}$ day of year ( $\operatorname{Jan} 9$ ), and decreases to the minimum of $2.2 \%$ on the $209^{\text {th }}$ day of 266 year (Jul 28) (Figure 3-6). 
267 The mean $S C D$ in Inner Tien Shan (IT) is $162.5 \pm 79.5$ days, while vast areas of high mountains

268 greater than $3000 \mathrm{~m}$ in IT, including the At-Bashi and the Kokshaltoo ranges, experience $S C D$

269 around $204.1 \pm 71.0$ days. The low plains to the western slope of those mountains have relative low

$270 S C D$, with a mean of $91.7 \pm 2.1$ days; while areas located in rain shadow of those mountains at the

271 eastern slope have mean $S C D$ of $11.8 \pm 3.9$ days. The maximum snow cover of $86.1 \%$ happens on

272 the $41^{\text {st }}$ day of year (Fed 10) and goes down to the minimum of $16.5 \%$ on the $209^{\text {th }}$ day of year (Jul

273 28) (Figure 3-9).

274 Northern Tien Shan (NT) has a mean SCD of 136.3 \pm 70.3 days, and the high mountains have

275 mean $S C D$ of $259.5 \pm 45.0$ days, while its low elevation plains have a mean $S C D$ of $81.4 \pm 25.6$

276 days. The valley in the southwestern part of NT between the Kirgiz Alatoo and the Moldo Too

277 ranges, as well as the valley in the southeastern part of NT between the Ketmen and the Kokshaltoo

278 ranges, have a mean $S C D$ of $23.7 \pm 13.7$ days, which are the lowest in NT, due to their location in

279 the rain shadow of mountains surrounding them. In general the snow cover in NT shrinks from the

280 peak of $80.7 \%$ on the $25^{\text {th }}$ day of year (Jan 25) to the minimum of $5.0 \%$ on the $209^{\text {th }}$ day of year (Jul

281 28) (Figure 3-7).

282 The climatic region of Issyk Kul Lake basin (IK) has a mean SCD of 108.6 197.2 days. The

283 high elevation mountains in the northern and southern part of IK have long $S C D(207.4 \pm 78.6$

284 days), while the low plains, surrounding the warm Issyk Kul Lake experience shorter $S C D$ than the

285 regional average, from $3.0 \pm 9.8$ days at the western lake shore to $81.0 \pm 23.4$ days at the eastern 
286 lake shore. The snow cover in IK reaches its maximum of $51.3 \%$ on the $41^{\text {st }}$ day of year (Feb 10) 287 and goes down to the minimum of $9.0 \%$ on the $209^{\text {th }}$ day of year (Jul 28) (Figure 3-8).

288 Central Tien Shan (CT) has a mean $S C D$ of $111.5 \pm 95.4$ days, where the high mountains have

289 high values of $206.4 \pm 83.2$ days, while the low elevation areas along foot of mountain ranges

290 having low values of $32.8 \pm 13.8$ day. The lowest $S C D(0-5$ days $)$ can be observed at the

291 southeastern part of CT bordering Tarim, as this part of CT is situated in the rain shadow of the

292 Samin Ula Mountains. Its maximum snow cover of $60.2 \%$ happens on the $9^{\text {th }}$ day of year (Jan 9)

293 while the minimum coverage of $9.6 \%$ occurs on the $209^{\text {th }}$ day of year (Jul 28) (Figure 3-11).

294 Eastern Tien Shan (ET) has a shorter mean $S C D(75.8 \pm 59.7$ days) than other climatic regions in

295 Tien Shan. Similar to other climatic regions, its high elevation mountain ranges experience long

296 time of snow cover $(212.6 \pm 72.6$ days). The ET can be further separated into a northern and a

297 southern part by the mountain ranges extending from west to east in the middle of the region. The

298 southern part (the Turfan basin) has much shorter $S C D$ (13.8 \pm 8.2 days) compared with the

299 northern (the Jungar basin) one (90.6 \pm 24.0 days). The snow cover in ET reaches its maximum

300 status of $59.4 \%$ at the beginning of a year, and then shrinks down to about $2 \%$ on the $110^{\text {th }}$ day of

301 year (Apr 20). The snow cover starts accumulating on about the $270^{\text {th }}$ day of year (Sept 27) (Figure

302 3-10).

303 Tarim (TR) is the climatic region with the shortest area weighted mean SCD (20.2 \pm 27.2 days).

304 It also has the highest coefficient of variation (1.35) of $S C D$ among all climatic regions in CA,

305 which suggests that snow only appears occasionally in most places in Tarim. The minimum value of

$306 S C D$ of 0.0 shows that there are places in TR where snow had not been observed by AVHRR 
307 sensors during the 23-years research period. Areas with the shortest $S C D(0-5$ days $)$ are mostly

308 located at the eastern part of TR in the Kumtag Desert, while relatively longer SCD (104.7 \pm 65.5

309 days) can be observed at high mountain ranges, e.g., the Kunlun Mountains in the southern part of

310 TR bordering the Tibetan Plateau. TR has much lower maximum snow coverage at about $27.9 \%$

311 compared with other climatic regions, happening on around the $9^{\text {th }}$ day of year (Jan 9) (Figure 3-3).

312 The snow cover goes down quickly to below $1 \%$ of the total area of TR on about the $50^{\text {th }}$ day of year

313 (Fed 19) and stay at similar values until about the $300^{\text {th }}$ day of year (Oct 27), with snow cover only

314 exists in high mountains during this time.

\section{$315 \quad$ 4.2.4 Pamir and surrounding areas}

316 Western Pamir (WP) has an area weighted mean $S C D$ of $83.7 \pm 87.5$ days, with large variation

317 within the region. The high mountains in the eastern part of WP have a mean $S C D$ of $238.0 \pm 47.4$

318 days, while the plains along the Amu Dar'ya River and its tributaries have a mean SCD of $10.9 \pm$

3197.9 days. Valleys surrounded by mountains in WP also experience low SCD at a similar level. Its

320 snow cover reaches the peak value of $56.4 \%$ on the $9^{\text {th }}$ day of year (Jan 9), and shrinks down to the

321 minimum of $3.1 \%$ on the $249^{\text {th }}$ day of year (Sept 6) (Figure 3-12).

322 Pamiro-Alai ranges (PA), at the northern Pamir, have a mean SCD of $162.6 \pm 86.0$ days, with

$32347.8 \%$ of its area higher than $3000 \mathrm{~m}$ have a mean $S C D$ of $237.5 \pm 52.6$ days. The relatively lower

324 mountain valleys in PA, for example, the Zaravshan Valley in the west, have lower SCD at $53.6 \pm$

32522.9 days. Similar to WP, snow coverage in PA also reaches the maximum value on the $9^{\text {th }}$ day of

326 year ( $\operatorname{Jan} 9)$ with a value of $80.6 \%$, and the minimum snow coverage on the $249^{\text {th }}$ day of year (Sept

327 6) with a value of $13.5 \%$ (Figure 3-13). 
328 Central Pamir (CP), with most of its areas higher than $3000 \mathrm{~m}$, has the longest mean $S C D$

329 (256.7 \pm 78.3 days) in all climatic regions. At maximum, $97.9 \%$ of CP is covered by snow on the

$33049^{\text {th }}$ day of year (Feb 18), while the lowest amount of snow cover (40.4\%) happens on the $257^{\text {th }}$ day

331 of year (Sept 14) (Figure 3-14).

332 Eastern Pamir (EP) has a shorter mean SCD (171.0 \pm 94.9 days) compared with CP, although it

333 is in the similar elevation range. Obstruction of moisture bearing westerly to EP by the high

334 mountains in nearby WP and CP causes the lower $S C D$ in EP. Though high values of $S C D$ (228.3

$335 \pm 80.5$ days) can still be observed at high mountain regions $(>3500 \mathrm{~m})$ in EP, the lower elevation

336 valleys $(1800 \mathrm{~m}-3500 \mathrm{~m})$ surrounded by mountains usually has quite short $S C D(38.5 \pm 42.2$

337 days), with the smallest values ( $0-5$ days) found in most of the eastern part, between the Sarikol

338 ranges and the Taxkorgan ranges, or to the east of the Taxkorgan range. EP has the maximum snow

339 coverage of $83.5 \%$ on the $57^{\text {th }}$ day of year (Feb 26) and the snow coverage shrinks down to the

340 minimum of $32.2 \%$ on the $257^{\text {th }}$ day of year (Sept 14) (Figure 3-15).

\section{$341 \quad 4.2$ Factors affecting seasonal snow cover duration}

342 It is well known that elevation, relative location to major mountains and latitude are the main factors

343 determining the spatial distribution of seasonal snow cover (Kotlyakov, 1997; Severskiy \&

344 Severskiy, 2003; Parajka et al., 2010). We revisit this topic with more comprehensive and

345 advanced data for CA, using $S C D$ as the representation of snow cover duration.

\section{$346 \quad$ 4.2.1 Snow cover duration and elevation}

347 Examination of the relationship between $S C D$ with elevation (Figure 4 and 5) for the whole CA

348 shows the positive correlation between them with a mean increasing rate of 2.3 days / $100 \mathrm{~m}$ 
349 (Pearson's $\mathrm{r}=0.34, \mathrm{p}$-value $=0.0$ ). The magnitude of the correlation varies across different

350 elevation zones and climatic regions.

351 Below $2000 \mathrm{~m}, S C D$ is not strictly increasing with elevation, especially for the elevation zone

352 below $1000 \mathrm{~m}$ (Figure 4). Climatic regions with substantial portions of flat areas below $1000 \mathrm{~m}$,

353 including KS, AD, SA and ET, have weakened positive relationships (KS and SA) or even negative

354 relationships (AD and ET) between $S C D$ and elevation in low elevation zone. TR and MA, as

355 climatic regions with large portion of flat areas, also have similar weakened positive relationships

356 between $S C D$ and elevation, for areas below $3000 \mathrm{~m}$ and below $2000 \mathrm{~m}$, respectively (Figure 5).

357 This could be caused by other factors, e.g. latitude, having a strong influence on $S C D$ distribution

358 for low elevated areas with small elevation changes, which will be discussed in following part of 359 this section.

360 Between $2000 \mathrm{~m}$ and $5000 \mathrm{~m}$, the positive relationship between $S C D$ and elevation is relatively

361 stable compared with areas under $2000 \mathrm{~m}$ (Figure 4). The mean increasing rate at this elevation

362 range is 5.8 days / $100 \mathrm{~m}$, which is much higher than the mean increasing rate for the whole CA, and

363 accounts for most of the correlation between $S C D$ and elevation.

364 Above $5000 \mathrm{~m}$, the values of $S C D$ in mountainous regions tend to stabilize at about 320 days (e.g.,

365 EP and PA) (Figure 5-15, 5-13) to 350 days (e.g., CT and CP) (Figure 5-11, 5-14) without any

366 increase with elevation. The stabilizing phenomenon is related to the fact that under $5 \mathrm{~km}$ spatial

367 resolution, most of the high elevation grid points with elevation greater than $5000 \mathrm{~m}$ are mainly

368 filled with perennial snow or glaciers (Figure 2-a). 
369

370

371

372

373 elevation zones below $3000 \mathrm{~m}$. In higher elevation the increasing rates tend to be higher, with the

374 strongest increasing rate of 15.3 days / degree exists in the elevation zone above $4000 \mathrm{~m}$ (Figure 7-

375 b).

377 Five different types of linear statistical models (Table 2-1) were fitted to $S C D$, elevation and

378 latitude data in each climatic region. Climatic regions were classified into three groups based on 379 comparisons of the performance of those models.

\subsubsection{Plain climatic regions}

381 KS (Figure 5-1) and AD (Figure 5-2) are two regions with the 'Only latitude' model performing 382 significantly better than the 'Only elevation' model. The adjusted- $\mathrm{R}^{2}$ values for the 'Only latitude' 383 model are 0.52 and 0.49 for $\mathrm{KS}$ and $\mathrm{AD}$, respectively, while the adjusted $\mathrm{R}^{2}$ values for the 'Only 384 elevation' model are 0.02 and 0.01 .

385 Segmented regression with the 'Breaking elevation' model shows a critical elevation at $\sim 1750 \mathrm{~m}$ for 386 both KS and AD, separating the relationship between $S C D$ and elevation to two parts. In the lower

387 elevation part, $S C D$ has large variations at the same elevation and smaller increasing rate of $S C D$

388 by elevation, while in the higher elevation part $S C$ increases with elevation consistently and more 389 quickly than in the lower elevation part. Both climatic regions have similar increasing rates at the 
390 higher elevation zone, which are 12.1 days / $100 \mathrm{~m}$ and 11.3 days / $100 \mathrm{~m}$, respectively.

391 Comparisons among the 'Elevation and latitude', 'Breaking elevation' and 'Breaking elevation and

392 latitude' (Table 2-1) models for these two climatic regions show that the performance of the first

393 one is at a similar level as the latter two, despite the latter two's more complex structure. Such a lack

394 of improvement of performance for complex models indicates that most of the variation of SCD in

395 the lower elevation part in these two climatic regions can be accounted for by the effect of latitude.

\subsubsection{Windward climatic regions}

397 Climatic regions other than KS and AD can be classified to two groups based on the criteria whether 398 a significant break of the relationship between $S C D$ and elevation exists in the elevation range from $3991000 \mathrm{~m}$ to $3000 \mathrm{~m}$ (see section 3.1.5). For SA (Figure 5-4), WT (Figure 5-6), NT (Figure 5-7), WP

400 (Figure 5-12), PA (Figure 5-13) and CP (Figure 5-14), the segmented regression with 'Breaking 401 elevation' and 'Breaking elevation and latitude' either cannot find a significant breaking point under 402 significance level $a=0.05$, or the resulting linear model does not perform better than the 403 corresponding simple linear model as shown by comparison of AICc, adjusted-R ${ }^{2}$ and ANOVA test 404 under significance level of 0.05 . This group was named as windward group since climatic regions in 405 this group are in general located to the windward side of nearby major mountain systems. In this 406 group, there are positive relationships between $S C D$ and elevation. The positive increasing rates are 407 not constant but increase with elevation until elevation reaches $\sim 5000 \mathrm{~m}$, and the changes in these 408 rates occur slowly and continuously.

\subsubsection{Leeward climatic regions}

410 For MA (Figure 5-5), IK (Figure 5-8), IT (Figure 5-9), CT (Figure 5-11), ET (Figure 5-10), and

411 EP (Figure 5-15), segmented linear models perform better than corresponding simple linear models.

412 This group was named as leeward group since these climatic regions are in general located to the 
413 leeward side of nearby major mountain systems. In this group, the increasing rates of SCD with

414 elevation are insignificant at low elevation zone, speed up at a certain critical elevation, and then

415 stabilize when the elevation reaches approximately $5000 \mathrm{~m}$.

416 The increasing rates of $S C D$ with elevation for MA are 1.2 days / $100 \mathrm{~m}$ and 15.9 days / $100 \mathrm{~m}$, for

417 areas below and above $2215 \mathrm{~m}$, respectively. In areas surrounding the Tien Shan Mountains, the

418 critical elevation separating the relationship between SCD and elevation can be observed in the

419 range from $2700-2900 \mathrm{~m}$ for different climatic regions. The increasing rates for the lower part vary

420 from 1.6 days / $100 \mathrm{~m}$ in CT to 5.5 days / $100 \mathrm{~m}$ in IK; while for higher part the increasing rates

421 vary from 11.5 days / $100 \mathrm{~m}$ in IT to 16.3 days / 100m in IK (Figure 6). EP, as in the leeward side

422 of Pamir Plateau, has the smallest increasing rate of $S C D$ for low elevation $(<2750 \mathrm{~m})$ at 0.4 days /

$423100 \mathrm{~m}$, while the increasing rate for high elevation part is 13.2 days / $100 \mathrm{~m}$, only 2 - 3 days smaller 424 than in MA, ET and CT.

425 TR has shorter $S C D$ at all elevation zones compared with any other climatic region in CA (Figure

426 5-3). The increasing rate of $S C D$ is also smaller than in other climatic regions, and shows a break at

427 around $3000 \mathrm{~m}$. The increasing rates are 1.4 days / $100 \mathrm{~m}$ and 8.8 days / $100 \mathrm{~m}$ for areas below and 428 above $3000 \mathrm{~m}$, respectively. Since several nearby mountains of the head water for Tarim River are 429 also included, the elevation range for TR goes up to higher than $5000 \mathrm{~m}$. TR has an exceptional low $430 S C D$ (<250 days) for areas above $5000 \mathrm{~m}$ because most of such high elevation areas are located at 431 its far southeastern border with Tibetan Plateau with relatively low amount of precipitation 432 (Kotlyakov, 1997; Aizen et al., in preparation). 


\section{3}

434 Leeward climatic regions tend to have shorter SCD at the same elevation compared with

435

436

437

438

439

440

441

442

\section{3}

444

445

\subsubsection{Comparison of snow cover duration between windward and leeward climatic regions}

corresponding windward climatic regions. MA has shorter mean values of $S C D$ at all elevation

zones than SA (Figure 8-a), and the differences are most distinct (up to 100 days) in $1000 \mathrm{~m}-3000$

m. EP also has shorter $S C D$ than other climatic regions in Pamir, with the highest difference of

about 145 days observed in the elevational range from 3000 m - 4000 m (Figure 8-c). In Tien Shan

(Figure 8-b) mean $S C D$ in windward regions are about 70 days longer than in leeward regions at

the elevations from $1000 \mathrm{~m}$ to $3000 \mathrm{~m}$, and about 20 days longer in the elevational range $3000 \mathrm{~m}$ -

4000m. For areas above 4000 m or below 1000 m, the leeward side has slightly longer mean $S C D$

than the windward side, with differences less than 20 days.

\subsubsection{Linear modeling of snow covering days}

To synthesize the relationship between $S C D$ with elevation and latitude, linear regression models

for $S C D$ using elevation and latitude as independent variables were fitted separately for plains,

windward and leeward climatic regions (Table 2-2). For plains and windward climatic regions, the

'Elevation and latitude' model was used, while for leeward climatic regions the 'Breaking elevation and latitude' model was used. Latitude has a similar effect on $S C D$ for all three types of regions.

Elevation has similar effect for plains and windward climatic regions. In leeward climatic regions, the general critical elevation separating zones with different types of relationships is $2335 \mathrm{~m}$

detected by segmented regression. At lower elevation, the increasing rate for $S C D$ with elevation is smaller (0.7 days / $100 \mathrm{~m})$ compared with the other two types of regions, though in higher elevation the $S C D$ increases at a much faster rate $(10.7$ days / $100 \mathrm{~m})$. 
454 It should noticed that the distribution of elevation gradient of snow cover duration ( $S C D / E l v)$ is

455 not homogeneous within each climatic region. For example, the mid-elevation (2000 m - $3000 \mathrm{~m})$

456 zone in WT and WP with orthogonal direction to the westerlies tend to have more prolonged SCD

457 and larger SCD/Elevation than at other altitudes. In CT and EP, areas landlocked by nearby

458 mountains tend to have longer SCD and smaller SCD/Elev than other areas in open environment.

459 The effect of "relative location" to major nearby mountains have been taken into account at a

460 regional scale by classification of climatic regions as windward or leeward, while the local scale

461 effect of "relative location" has not been considered. To further analyze the influence of the

462 "relative location" the estimation of appropriate indices for the local scale effect might be required.

463 A combination of elevation, latitude and relative location might be the basis for a geographical

464 distributed statistical model for long term snow cover distribution.

\section{$465 \quad 4.3$ Trend of seasonal snow cover change}

466 The dynamics of area weighted mean monthly SCAP for the whole CA (Figure 9) during the past

46723 years show no significant trend of change. The area weighted mean annual SCAP for the whole

468 CA dropped down to its minimum in 1988, increased to its maximum in 1993, then stayed relatively

469 stable around the long term mean value of $25 \%$. The Theil-Sen regression and the Mann-Kendal test

470 analysis of gridded SCD, SCOD, SCMD, SCmax and DSCmax were conducted, showing no

471 significant trend of change for SCmax and DScmax almost everywhere in the research area during

472 the period from 1986 to 2008. For the whole CA, SCD, SCOD and SCMD have area weighted mean

473 change rates of -0.02 days / year, -0.06 days / year and -0.01 days / year, respectively. Spatial

474 patterns of the SCD, SCOD and SCMD changes are heterogeneous, with large portions of the

475 research area experience no significant change, while strong significant change with different

476 directions happened in different regions in CA (Figure 10). 
477 Below $2000 \mathrm{~m}$, the mean trend of change $(\alpha S C D)$ for areas with significant change is slightly less

478 than 0 days / year, with a large standard deviation of $\alpha S C D$ of $\sim 1$ days / year. The $\alpha S C D$ decreases

479 with increasing elevation, with the lowest value of -1.57 days / year observed in areas with elevation

480 above $4000 \mathrm{~m}$ (Figure 11-a). The values of $\alpha S C D$ for most climatic regions are either around or

481 below 0 days / year, except KS, ET and CT, which have $\alpha S C D$ at $0.13,0.13$ and 0.85 days / year,

482 respectively (Figure 11-b).

$483 \quad$ 4.3.1 Areas with decreasing seasonal snow duration

484 Vast areas of southern KS, northern AD, SA and MA experienced decreases of SCD. There are two 485 main clusters with significant decreases of SCD: 1) the Aral Sea region, where SCD decreased at a 486 rate of -1.43 days / year while SCMD shifted earlier with greater extent to the east and southwest, at 487 a rate of -1.00 days / year; 2) upper reach of the Orb River in the southwestern part of SA, where 488 SCD decreased at a mean rate of -1.56 days / year, with later SCOD (0.99 days / year) and earlier $489 \operatorname{SCMD}(-0.89$ days / year).

490 Significant decrease in SCD is observed in Tien Shan. From ET and CT in the eastern branch of 491 Tien Shan, to IT, IK, NT and WT in the western branch of Tien Shan, SCD decreased in areas above 4922000 m (Figure 11-c-6 to Figure 11-c-11). A cluster of significant SCD decreases is observed in 493 the mountains between ET and CT, with a mean rate of decreasing SCD at -1.16 days / year, 494 associated with later SCOD (0.68 days / year) and earlier SCMD (-0.73 days / year). In contrast, 495 SCD increased in the lower elevation areas $(<3000 \mathrm{~m})$ in ET and CT (Figure 11-c-10 and Figure 496 11-c-11).

497 Another cluster of significant decreasing SCD is located in the mountains among southwestern NT, 498 eastern WT and IT, with a mean rate of -1.18 days / year. In eastern WT mountains (> $3000 \mathrm{~m})$, 
499 significant decrease of SCD occurred with an average rate of -1.22 days / year, associated with 500 postponed SCOD (0.60 days / year) and earlier SCMD (-0.94 days / year). In southwestern NT

501 mountains $(2000-4000 \mathrm{~m})$, SCD decreased with a rate of -1.05 days / year, in companion with both

502 later SCOD (0.63 days / year) and earlier SCMD (-0.75 days / year). SCD decreased nearly

503 everywhere in IT, especially at its western and southern high mountains at elevation range from

$5042500 \mathrm{~m}$ to $4500 \mathrm{~m}$, with an average rate of -1.28 days / year. Decreases of SCD in those areas are

505 mainly associated with earlier SCMD with a mean rate of -0.92 days / year. SCOD also turned later,

506 but in a smaller area mainly at its southern high mountains with elevation greater than $3000 \mathrm{~m}$, and

507 with a smaller magnitude of 0.72 days / year.

508 Mountainous areas with elevation above $3000 \mathrm{~m}$ in Pamir, as well as in PA, which is the transition

509 zone between Pamir and Tien Shan, experienced significant decreasing SCD (Figure 11-c-12 to

510 Figure 11-c-15) with a mean rate of -1.59 days / year. In PA, SCD decreased significantly with an

511 average rate of -1.28 days / year associated with earlier SCMD (-0.77 days / year) in the eastern end

512 of the valley with high elevation (> $2500 \mathrm{~m}$ ). In WP, the eastern high mountains bordering CP and

513 EP at elevation higher than 3000 m experienced decreasing SCD with a mean speed of -1.78 days /

514 year. SCOD also shifted later with a mean rate of 0.75 days / year in those areas while SCMD

515 moved earlier with a rate of -0.80 days / year. Most parts of CP, especially its southern part with

516 elevation higher than $4000 \mathrm{~m}$, experienced significant decrease of SCD at a mean rate of -0.80 days

517 / year. The dominating feature of snow cover change in EP is the widespread significant trend of

518 decreasing SCD at a mean rate of -1.46 days / year, associated with delayed SCOD across different

519 elevation zone from $2000 \mathrm{~m}$ to higher than $5000 \mathrm{~m}$. The mean magnitude of change for the trend of

520 SCOD is 0.84 days / year, with stronger magnitude at higher elevation, especially at the elevation

521 range $4000-5000 \mathrm{~m}$. There is less number of grid points with significant trend of change for SCMD,

522 which mostly clustered in the center of EP with a mean change rate of -0.85 days / year. 
523 The decreasing SCD in high mountains in Altai, Tien Shan and Pamir in the research period from

5241986 to 2008, can result in a change of hydrological regime in CA, as less water is available stored

525 in seasonal snow cover in the cold season. The earlier SCMD, associated with a significant increase

526 of spring air temperature in those mountain regions might lead to a change of the timing and

527 seasonal distribution of stream flow.

\section{$528 \quad$ 4.3.2 Areas with increasing seasonal snow duration}

529 Increasing SCD can be observed in the northeastern part of KS and the northwestern part of SA,

530 where the center of Siberian High (north of $48^{\circ} \mathrm{N}$, east of $65^{\circ} \mathrm{E}$ ) in winter is situated (Jeong et al.,

531 2011; Hasanean et al., 2013). Those areas experienced an increase of SCD at a rate of 0.96 days /

532 year, associated mainly with later SCMD (0.71 days / year).

533 Increased SCD is also observed at low elevational regions below $2000 \mathrm{~m}$ in CT and ET, while

534 decreased SCD is observed in their high mountain areas above $2000 \mathrm{~m}$ (Figure 11-c-10 and Figure

535 11-c-11). In the southeastern part of CT along its border with Tarim at the elevation zone of 1000 -

$5362000 \mathrm{~m}$, the SCD increased with a mean rate of 1.52 days / year, in companion with earlier SCOD (-

5370.64 days / year) and later SCMD (0.85 days / year). In the northern and northeastern part of ET,

538 significant increase of SCD is observed across different elevations with an average rate of 1.58 days

539 / year. The increasing trend of SCD is associated with earlier SCOD (-1.01 days / year) and later

$540 \quad \operatorname{SCMD}$ (0.92 days / year).

541 In addition, significant increases of SCD occurred at mid-elevation areas in the western parts of the

542 climatic regions WT, PA and WP. In WT, areas to the west of the Ugamskiy Range and the

543 Chatkalskiy Range in the elevation range of 1000 - 2000 m (Figure 11-c-6) experienced increases

544 of SCD with an average rate of 1.15 days / year, associated with earlier SCOD at an average rate of -

5450.82 days / year; while SCMD did not have significant trend. In PA, there exist patches of places 
546 with increasing SCD (1.24 days / year) associated with earlier SCOD (-0.72 days / year) in the

547 western opening of the valley at the elevation range $1000 \mathrm{~m}-2000 \mathrm{~m}$ (Figure 11-c-13). In the

548 northwestern part of WP bordering PA, areas to the west of mountain ranges at elevation range 1000

$549 \mathrm{~m}-3000 \mathrm{~m}$ (Figure 11-c-12) experienced an increase of SCD at an average rate of 0.83 days / year,

550 as well as SCOD shifting earlier with a mean rate of -0.72 days / year.

\section{$551 \quad$ 4.4 Seasonal snow cover change and climate change}

552 To validate the evaluated snow cover changes for the period of 23 years, we analyzed the climatic

553 changes in different sub-regions of CA in association with statistically significant snow cover

554 changes. Areas surrounding the Aral Sea have experienced significant decrease of SCD, mainly

555 associated with earlier SCMD. The spring temperature in this region increased with a rate of $0.09^{\circ} \mathrm{C}$

556 / year, while the winter precipitation decreased with a rate of $-0.55 \mathrm{~mm} /$ year (Figure 12-a). In the

557 Altai climatic regions, especially SA, SCD decreased significantly, associated with later SCOD and

558 earlier SCMD. Such changes can be attributed to the increase of air temperature, especially the

559 spring air temperature with a significant increasing rate of $0.07{ }^{\circ} \mathrm{C} /$ year (Figure 12-b).

560 In high mountains of Tien Shan and Pamir, SCD decreased significantly mainly associated with

561 earlier SCMD, though Central Pamir was also affected by widespread delayed SCOD. Linear trend

562 analysis suggests that both Pamir and Tien Shan have experienced significant increases of spring

563 temperature at rates of $0.06{ }^{\circ} \mathrm{C} /$ year and $0.05^{\circ} \mathrm{C} /$ year, respectively (Figure 12-c and 12-d), while

564 the autumn and winter air temperature and seasonal precipitation (autumn, winter and spring) do not

565 have significant changes.

566 Comparisons of the seasonal temperature and precipitation trends for regions with significant

567 decreasing SCD suggests that the increasing spring air temperature is closely associated with the

568 decreasing SCD. A positive feedback loop might lead to such association, as warming air 
569 temperature can lead to increasing melt while decreasing snow cover extent can result in higher

570 surface albedo and increasing air temperature. This also explains the more widespread and stronger

571 trend of decreasing SCMD (earlier snow melt) compared with the trend of increasing SCOD (later

572 beginning of snow accumulation) (Figure 10-c and 10-b).

573 Significant increase of SCD can be observed in the northeastern Kazakh Steppe, accompanied by

574 delayed SCMD. Several studies have reported an increase of Eurasian snow cover after the mid-

575 1990s (Jeong et al., 2011), especially in Siberia which is close to the northeastern KS. The Siberian

576 High (SH) has seen a resurgence in recent years since the mid-1990s (Jeong et al., 2011) after a

577 long term decline from the late 1960s to the early 1990s (Panagiotopoulos et al., 2005; Hasanean

578 et al., 2013). Cohen and Entekhabi (1999) linked changes in Eurasian snow cover with variability in

579 the extent of the SH, as extensive Eurasian snow cover lead to expanded extent of SH. Thus, the

580 increased snow cover in southern Siberia might be the cause for a bouncing back of the SH (Cohen

581 et al., 2010 and Jeong et al., 2011). The precipitation in March increased significantly with a rate

582 of $0.59 \mathrm{~mm} /$ year while air temperature experienced a non-significant weak increase and stayed

583 below freezing in general (Figure 12-e). Such an increase of precipitation in early spring can lead to

584 an extension of the snow season and delayed SCMD. SCD also increased significantly in the low

585 elevation areas between Tarim and Central Tien Shan and in the low elevation areas in Eastern Tien

586 Shan. The winter temperature at this region decreased at a rate of $-0.06{ }^{\circ} \mathrm{C} /$ year, while winter

587 precipitation increased at a rate of $0.17 \mathrm{~mm} /$ year (Figure 12-f), which is in favor of increasing

588 SCD during the research period. 


\section{Discussion}

\subsection{Comparison with historical snow cover regime studies based on in-situ observations}

Kotlyakov et al. (1997) described the snow cover regime all over the world based on regular ground observation data from the 1960s to the 1980s. Spatial distribution of the number of snow covered days (Nsn, similar as SCD in this study) is found to be related with altitude, exposition of macroslope relative to trajectories of major moisture flow, and latitude. The latitudinal gradient for Nsn is 5 to 9.5 days / degree with a mean of 8 days / degree for the Northern Hemisphere, comparable with the latitudinal gradient of SCD ( 9 days / degree for areas below $3000 \mathrm{~m})$ reported for CA in this study. Leeward slopes tend to have lower Nsn compared with windward slopes, with one example showing that the mean Nsn in the western part of Pamir is 250 - 300 days on $3500 \mathrm{~m}$, in contrast with 40 - 50 days on the same elevation in the eastern part of Pamir. The values reported in this example (Kotlyakov et al., 1997) is comparable with what we found in presented study (Figure 8c). Average altitudinal gradient of Nsn varies across different slopes, with higher values in leeward slopes than in windward slopes. In general, this study provides an update of the description about the snow cover regime in CA based on recent remote sensing data.

\subsection{Comparison with snow cover regime studies based on satellite observations}

A series of studies analyzed historical snow cover change in the 20th century for the Northern Hemisphere mainly based on NOAA weekly snow cover extent (SCE) climate data record (CDR) (Robinson et al., 1993; Brown \& Robinson, 2011), as well as in-situ measurements (Groisman et al., 1994; Brown, 2000; Dye 2002; Brown \& Robinson, 2011). A common finding of these studies is that the SCE decreased systematically in the Eurasia continent since the 1970s, especially in March and April. Such decrease is mainly driven by the warming of air temperature, and the 
611 feedback loop among snow cover, radiative balance and spring air temperature (Groisman et al.,

612 1994). Though the results of those studies cannot be directly compared with presented study, due to

613 different spatial and temporal coverage, different spatial resolution and different summary statistics

614 for snow cover, the general decrease of spring snow cover in companion with increasing spring air

615 temperature aligns with our findings of decreasing SCD in CA mountainous areas well.

616 There also exists several publications about snow cover change in sub-regions of CA. Aizen et al.

617 (1997) analyzed the snow cover change from 1940 to 1991 using in-situ observations in 110 stations

618 in the Tien Shan region, suggesting a general decrease of snow resources nearly everywhere in the

619 research region, with snow duration down by 9 days. Such decrease of snow resource is in

620 companion with increasing air temperature, despite a slight increase of precipitation. Khan and

621 Holko (2009) analyzed snow cover changes in the Aral Sea Basin based on NOAA weekly SCE

622 CDR, re-analysis data and station observations, suggesting decreasing trend of SCE from 1971 to

623 2006. Our previous study about snow cover changes in Amu Dar'ya Basin from 1986 to 2008

624 (ZHOU et al., 2013) reported significant decreasing trends of SCD in mountainous regions, mainly

625 accompanied with earlier SCMD, while SCOD has shifted earlier in WP and delayed in CP. Results

626 about snow cover changes presented in this study confirm with previous findings of decreasing

627 snow cover, especially in spring, while providing an extended spatial coverage over the whole CA,

628 as well as finer spatial resolution. Even though the results reported in this paper might not be

629 directly compared with previous findings due to differences in underlying data, research area, and

630 research period, the general decreases of seasonal now cover in mountains presented in this paper

631 correspond to previous findings well.

632 An independent analysis of snow cover change in the Central Asian Republics (CARs) from 1986 to

6332014 were conducted by Dietz et al. (2014) based on AVHRR imageries (referred as D2014 in later 
634 texts). Summary statistics for snow cover extent and timing characteristics, including SCD, SCDES

635 and SCDLS (same as SCD, SCOD and SCMD in this study) were calculated at each $100 \mathrm{~m}$

636 elevation zone within the CARs, and within different catchment groups. Trends of the summary

637 statistics were analyzed using Mann-Kendal test. The results show that SCMD shifted earlier

638 significantly in upstream catchments of Amu Dar'ya and Syr Dar'ya, as well as in the elevation

639 range between 2500 and $3200 \mathrm{~m}$, which is in agreement with our previous work and the results of

640 this study in general. It is reported that SCOD moved earlier significantly all over CARs, and no

641 significant trend of SCD change can be detected in any catchment group or elevation zone, which

642 differs from our findings. In this study, within the boundary of CARs, significantly decreased SCD

643 was observed in mountainous areas of Tien Shan and Pamir, while only patches in WP and WT

644 experienced SCOD shifted earlier. The disagreement might come from the slightly different

645 temporal coverage of the two studies (1986 to 2008 in the presented study vs. 1986 to 2014 in

646 D2014). Another possible cause of the difference is the different calculation unit used when

647 conducting trend tests. In D2014, trend calculation was conducted at each $100 \mathrm{~m}$ elevation zone

648 across the whole CARs and different catchment groups within the CARs. As shown in our results,

649 the trend of change for snow cover statistics exhibits large spatial variability across/within different

650 climatic regions and altitudinal ranges. Calculation conducted at the grid level as in the presented

651 study can preserve and quantify such spatial variability, enabling further analysis of the dependence

652 of trends on climatic and topographic factors, while calculation conducted at catchment groups and

$653100 \mathrm{~m}$ elevation zones within the political boundaries might lump areas with different directions of

654 change together, resulting in diluted or altered signals of changes. 


\section{Conclusion}

656 Analysis of the long term mean snow cover statistics shows that the whole CA has area weighted

657 mean values of $S C D, S C O D, S C M D$ of $95.2 \pm 65.7$ days, Nov $23^{\text {rd }} \pm 26$ days and Mar $7^{\text {th }} \pm 36$

658 days. More than $73 \%$ of the areas in CA have SCmax greater than $95 \%$ before Jan $26^{\text {th }}$. High

659 mountainous regions of Altai, Tien Shan and Pamir, accounting for $\sim 2.8 \%$ of total area in CA, have

$660 S C D$ longer than 240 days and DSCmax before Jan $5^{\text {th }}$. The northern part of CA, from Kazakh

661 Steppe to Siberian Altai and Mongolian Altai, have SCD in the range of 90 - 240 days, while the

662 southern part of CA have SCD in the range of $0-90$ days. Deserts and rain shadows of major

663 mountains, which also accounts for about $27.0 \%$ of total area in CA, have SCD in the range of 0 -

66430 days.

665 Simple linear regression and segmented linear regression analysis show that elevation is the most

666 significant factor determining the distribution of $S C D$ among elevation, latitude and relative

667 location to major mountains. The relationship between $S C D$ and elevation varies according to the

668 relative location to nearby major mountain systems. Latitude has a strong influence in SCD in plain

669 climatic regions (Kazakh Steppe and Aral-Caspian Desert). Climatic regions other than KS and AD

670 were classified as windward and leeward regions, based on the different types of relationship

671 between SCD and elevation. A positive relationship with a magnitude of 5.9 days / $100 \mathrm{~m}$ can be

672 found for plains and windward side mountainous regions, while the magnitude changes from 0.7

673 days / $100 \mathrm{~m}$ to 10.0 days / $100 \mathrm{~m}$ at $\sim 2335 \mathrm{~m}$ for leeward side mountainous regions. Latitude

674 affects the distribution of $S C D$ with a magnitude of $9-10$ days / degree. 
675 Analysis of the snow cover change for the period from 1986 to 2008 reveals several areas with 676 different types of snow cover change. Analysis of climate changes in areas with different types of

677 snow cover change show that the climate changes are in accordance with the snow cover changes.

678 Increase of SCD can be observed in the northeastern Kazakh Steppe with a rate of 0.96 days / year,

679 mainly associated with later SCMD and a decrease of air temperature in March. SCD also increased

680 in lower elevation area below $2000 \mathrm{~m}$ in Central Tien Shan and Eastern Tien Shan with a rate of 681 about 1.5 days / year, as well as in mid-elevation areas (1000 m-3000 m) in Western Tien Shan 682 (1.15 days / year), Pamiro-Alai (1.24 days / year) and Western Pamir (0.83 days / year), associated 683 with both earlier SCOD and later SCMD. Decreased SCD can be observed at areas surrounding the 684 Aral Sea with a rate of -1.43 days / year while SCMD shifted earlier in the same place though with 685 greater geographical extent. Mountains in Altai, Tien Shan and Pamir also experienced significant 686 decreases of SCD, with rates of -1.56 days / year, -1.16 days / year and -1.59 days / year, 687 respectively. Such decreases of SCD mainly associated with earlier SCMD, with rates of -0.89 days 688 / year, -0.73 days / year and -0.81 days / year for mountainous areas in Altai, Tien Shan and Pamir, 689 respectively. The decreases of SCD and the SCMD shifting earlier can be attributed mainly to the 690 significant increase of spring air temperatures in the research period between 1986 and 2008.

\section{Acknowledgement}

692 This research was supported by grants from the National Science Foundation AGS-1304898 and the 693 National Aeronautics and Space Administration NNXO8AL686. 
695 Tables

696 Table 1 Region definitions as longitudinal and latitudinal ranges

\begin{tabular}{|c|c|c|c|}
\hline Region & description & latitudinal range & $\begin{array}{l}\text { longitudinal } \\
\text { range }\end{array}$ \\
\hline Aral Sea & Places surrounding Aral Sea & $52.5^{\circ} \mathrm{N}-67.5^{\circ} \mathrm{N}$ & $42.5^{\circ} \mathrm{E}-47.5^{\circ} \mathrm{E}$ \\
\hline Northeastern KS & Northeastern part of Kazakh Steppe & $50^{\circ} \mathrm{N}-55^{\circ} \mathrm{N}$ & $70^{\circ} \mathrm{E}-82.5^{\circ} \mathrm{E}$ \\
\hline Altai & $\begin{array}{l}\text { Siberian Altai-Sayan } \\
\text { and Mongolian Altai }\end{array}$ & $47.5^{\circ} \mathrm{N}-52.5^{\circ} \mathrm{N}$ & $80^{\circ} \mathrm{E}-95^{\circ} \mathrm{E}$ \\
\hline Pamir & Central Pamir and Eastern Pamir & $37.5^{\circ} \mathrm{N}-40^{\circ} \mathrm{N}$ & $72.5^{\circ} \mathrm{E}-75^{\circ} \mathrm{E}$ \\
\hline $\begin{array}{l}\text { Western mountains of } \\
\text { Tien Shan }\end{array}$ & $\begin{array}{l}\text { junction of major mountains among } \\
\text { Tien Shan climatic regions }\end{array}$ & $40^{\circ} \mathrm{N}-42.5^{\circ} \mathrm{N}$ & $70^{\circ} \mathrm{E}-80^{\circ} \mathrm{E}$ \\
\hline $\begin{array}{l}\text { Boundary zone among } \\
\text { Central Tien Shan, } \\
\text { Tarim and Eastern Tien } \\
\text { Shan }\end{array}$ & $\begin{array}{c}\text { Lower plains spanning from Central } \\
\text { Tien Shan to Tarim and Eastern Tien } \\
\text { Shan }\end{array}$ & $40^{\circ} \mathrm{N}-42.5^{\circ} \mathrm{N}$ & $80^{\circ} \mathrm{E}-90^{\circ} \mathrm{E}$ \\
\hline
\end{tabular}


Table 2-1 Linear models for $S C D$ with elevation and latitude

\begin{tabular}{|c|c|c|c|}
\hline ID & short name & formula in R style & description \\
\hline 1 & Only latitude (OL) & $\mathrm{SCD} \sim$ Lat & $S C D$ depends on latitude only \\
\hline 2 & Only elevation $(\mathrm{OE})$ & SCD Elev & $\begin{array}{l}S C D \text { depends on elevation } \\
\text { only }\end{array}$ \\
\hline 3 & $\begin{array}{l}\text { Elevation and latitude } \\
\text { (EL) }\end{array}$ & $\mathrm{SCD} \sim$ Elev + Lat & $\begin{array}{l}S C D \text { depends on both } \\
\text { elevation and latitude }\end{array}$ \\
\hline 4 & $\begin{array}{l}\text { Breaking elevation } \\
\text { (BE) }\end{array}$ & SCD Elev : I(Elev > critical_elevation) & $\begin{array}{l}S C D \text { depends on elevation } \\
\text { only, with the relationship } \\
\text { breaks at a certain critical } \\
\text { elevation }\end{array}$ \\
\hline 5 & $\begin{array}{l}\text { Breaking elevation and } \\
\text { latitude (BEL) }\end{array}$ & $\begin{array}{l}\text { SCD } \sim \text { Elev : I(Elev > critical_elevation })+ \\
\text { Lat }\end{array}$ & $\begin{array}{l}S C D \text { depends on elevation and } \\
\text { latitude, with the relationship } \\
\text { breaks at a certain critical } \\
\text { elevation }\end{array}$ \\
\hline
\end{tabular}

699

700

701

702

703

Table 2-2 Regression result for $S C D$ with elevation and latitude for different types of climatic regions

\begin{tabular}{ccc}
\hline Region name & Regression model & $\mathrm{R}^{2}$ \\
\hline Plains & $\mathrm{SCD}=0.0585 \mathrm{elev}+9.6778$ lat -380.0674 & 0.8927 \\
Leeward side & $\mathrm{SCD}=0.0068 \mathrm{elev}+10.0256$ lat $-388.9821(\mathrm{elev}<2335)$ & 0.7181 \\
mountainous regions & $\mathrm{SCD}=0.1004$ elev +10.0256 lat $-388.9821(\mathrm{elev}>=2335)$ & 0.8234 \\
Windward side & $\mathrm{SCD}=0.0611 \mathrm{elev}+9.1655$ lat -366.9686 &
\end{tabular}




\section{Figures}

708 Figure 1 Topography and climatic regions in central Asia (CA)

709 Main map shows the digital elevation model derived from GGIAR SRTM data and division of

710 climatic regions in CA:

711 1: Kazakh Steppe (KS), 2: Aral-Caspian Desert (AD), 3: Tarim (TR); 4: Siberian Altai-Sayan (SA),

712 5: Mongolian Altai (MA); 6. Western Tien Shan (WT), 7: Northern Tien Shan (NT), 8: Issyk Kul

713 (IK), 9: Inner Tien Shan (IT), 10: Eastern Tien Shan (ET), 11: Central Tien Shan (CT); 12: Western

714 Pamir (WP), 13: Pamiro-Alai (PA), 14: Central Pamir (CP), 15: Eastern Pamir (EP)

715 Grey triangles show location of ground snow survey data

716 Inset maps A), B) and C) show major mountain systems in Altai, Tien Shan and Pamir.

717 Figure 2-a Perennial Snow Cover Area Percentage (PSCAP) from 1986 to 2008 in CA

718 Figure 2-b Long-term mean Snow Covering Days (SCD) from 1986 to 2008 in CA

719 Figure 2-c Long-term mean Snow Cover Onset Date (SCOD) from 1986 to 2008 in CA

720 Figure 2-d Long-term mean Snow Cover Melt Date (SCMD) from 1986 to 2008 in CA

721 Figure 2-e Long-term mean Maximum Snow Cover Area Percentage (SCmax) from 1986 to

$722 \quad 2008$ in CA

723 Figure 2-f Long-term mean Day of Maximum Snow Cover (DSCmax) from 1986 to 2008 in CA

724 Figure 3 Long-term mean 8-day SCAP and maximum SCAP for each climatic region 
725 The star shows the date for maximum SCAP, while light blue span indicates 2 std of SCAP

726 Figure 4 Scatterplots of long-term mean SCD against elevation in CA

727 red solid line showing the moving mean, dash lines showing the extent of 2 moving std

728 upper panel depicting the histogram and density of SCD distribution

729 right panel depicting the histogram and density of elevation distribution

730 Figure 5 Scatterplots of long-term mean SCD against elevation in each climatic region

731 red solid line showing the moving mean, dash lines showing the extent of 2 moving std

732 Figure 6 Increasing rates of $S C D$ by elevation in leeward climatic regions

733 Figure 7-a Relationship between long-term mean SCD and latitude in condition of elevation

734 Figure 7-b Increasing rate of $S C D$ by latitude in different elevation zones

735 Figure 8-a SCD distribution between windward side and leeward side climatic regions in Altai

736 Windward side: Siberian Altai-Sayan (SA); Leeward side: Mongolian Altai (MA)

737 Figure 8-b SCD distribution between windward and leeward climatic regions in Tien Shan

738 Windward side: Western Tien Shan (WT), Northern Tien Shan (NT); Leeward side: Issyk Kul (IK),

739 Central Tien Shan (CT), Eastern Tien Shan (ET) Inner Tien Shan (IT)

740 Figure 8-c SCD distribution between windward side and leeward side climatic regions in

$741 \quad$ Pamir 
742 Windward side: Western Pamir (WP), Pamiro-Alai (PA), Central Pamir (CP); Leeward side: Eastern

743 Pamir (EP)

744 Figure 9 Monthly SCAP in CA from 1986 to 2008

745 Figure 10-a Trend of SCD change detected by Theil-Sen regression

746 Only grids showing significant changes under Mann-Kendal test with significant level of 0.05 were

747 shown.

748 Figure 10-b Trend of SCOD change detected by Theil-Sen regression

749 Only grids showing significant changes under Mann-Kendal test with significant level of 0.05 were 750 shown.

751 Figure 10-c Trend of SCMD change detected by Theil-Sen regression

752 Only grids showing significant changes under Mann-Kendal test with significant level of 0.05 were 753 shown.

754 Figure 11-a Box plots of trend of SCD in different elevation ranges

755 Figure 11-b Box plots of trend of SCD in different climatic regions

756 Figure 11-c Box plots of trend of SCD in different elevation ranges within each climatic region

757 Figure 12-a Air temperature and precipitation change in areas surrounding Aral Sea

758 Figure 12-b Air temperature and precipitation change in Altai

759 Figure 12-c Air temperature and precipitation change in western mountains of Tien Shan

760 Figure 12-d Air temperature and precipitation change in Pamir

761 Figure 12-e Air temperature and precipitation change in Northeastern Kazakh Steppe 
762 Figure 12-f Air temperature and precipitation change in in boundary zone among Central

763 Tien Shan, Tarim and Eastern Tien Shan

764 


\section{References}

Aizen, V. B., Aizen, E. M., \& Melack, J. M. (1995). Climate, snow cover, glaciers, and runoff in the Tien Shan, Central Asia. Water Resources Bulletin, 31(6), 1113-1129.

Aizen, V. B., Aizen, E. M., \& Melack, J. M. (1996). Precipitation, melt and runoff in the northern Tien Shan. Journal of Hydrology, 186(1-4), 229-251.

Aizen, V. B., Aizen, E. M., Melack, J. M., \& Dozier, J. (1997). Climatic and hydrologic changes in the Tien Shan, central Asia. Journal of Climate, 10(6), 1393-1404. http://doi.org/10.1175/1520-0442(1997)010<1393:CAHCIT>2.0.CO;2

Aizen, E. M. E., Aizen, V. B. V., Melack, J. M., \& Krenke, A. N. (2000). Heat exchange during snow ablation in plains and mountains of Eurasia. Journal of Geophysical Research, 105(D22), 013-027. Retrieved from http://onlinelibrary.wiley.com/doi/10.1029/2000JD900279/full

Aizen, V. B. (2004). Association between atmospheric circulation patterns and firn-ice core records from the Inilchek glacierized area, central Tien Shan, Asia. Journal of Geophysical Research, 109(D8). http://doi.org/10.1029/2003JD003894

Aizen, V. B., Aizen, E., Fujita, K., Nikitin, S. A., Kreutz, K. J., \& Takeuchi, L. N. (2005). Stableisotope time series and precipitation origin from firn-core and snow samples, Altai glaciers, Siberia. Journal of Glaciology, 51(175), 637-654. http://doi.org/doi:10.3189/172756505781829034

Aizen, V. B., Mayewski, P. a., Aizen, E. M., Joswiak, D. R., Surazakov, A. B., Kaspari, S., ... Finaev, A. (2009). Stable-isotope and trace element time series from Fedchenko glacier (Pamirs) snow/firn cores. Journal of Glaciology, 55(190), 275-291. http://doi.org/10.3189/002214309788608787

Aizen, V. B., Aizen, E. M., ZHOU, H., in preparation, Climate changes in central Asia in the $20^{\text {th }}$ century

Barnett, T. P., Adam, J. C., \& Lettenmaier, D. P. (2005). Potential impacts of a warming climate on water availability in snow-dominated regions. Nature, 438(7066), 303-9. doi:10.1038/nature04141

Böhner, J., \& Bohner, J. (2006). General climatic controls and topoclimatic variations in Central and High Asia. Boreas., 35(2), 279-295. http://doi.org/10.1080/03009480500456073

Brown, R. D. (2000). Northern Hemisphere Snow Cover Variability and Change, 1915-97. Journal of Climate, 13(13), 2339-2355. doi:10.1175/1520-0442(2000)013<2339:NHSCVA>2.0.CO;2 
796

797

798

799

800

801

802

803

804

805

806

807

808

809

810

811

812

813

814

815

816

817

818

819

820

821

822

823

824

825

826

827

828

829

830

831

Brown, R. D., \& Robinson, D. a. (2011). Northern Hemisphere spring snow cover variability and change over 1922-2010 including an assessment of uncertainty. The Cryosphere, 5(1), 219229. http://doi.org/10.5194/tc-5-219-2011

Bryson, R. (1986). Airstream Climatology of Asia. In Y. Xu (Ed.), Proceedings of International Symposium on the Qinghai-Xizang Plateau and Mountain Meteorology SE - 36 (pp. 604-619). American Meteorological Society. http://doi.org/10.1007/978-1-935704-19-5_36

Chapin, F. S., Sturm, M., Serreze, M. C., McFadden, J. P., Key, J. R., Lloyd, a H., ... Welker, J. M. (2005). Role of land-surface changes in arctic summer warming. Science (New York, N.Y.), 310, 657-660. http://doi.org/10.1126/science.1117368

Chevallier, P., Pouyaud, B., Mojaïsky, M., Bolgov, M., Olsson, O., Bauer, M., \& Froebrich, J. (2014). River flow regime and snow cover of the Pamir Alay (Central Asia) in a changing climate. Hydrological Sciences Journal, (July), 1-16. http://doi.org/10.1080/02626667.2013.838004

Choi, G., Robinson, D. a., \& Kang, S. (2010). Changing Northern Hemisphere Snow Seasons. Journal of Climate, 23(19), 5305-5310. doi:10.1175/2010JCLI3644.1

Cohen, J., \& Entekhabi, D. (1999). Eurasian snow cover variability and Northern Hemishpere climate predictability. Geophysical Research Letters, 26(3), 345-348. http://doi.org/10.1029/1999GL900200

Cohen, J., Foster, J., Barlow, M., Saito, K., \& Jones, J. (2010). Winter 2009-2010: A case study of an extreme Arctic Oscillation event. Geophysical Research Letters, 37(July), 1-6. doi:10.1029/2010GL044256

Dietz, A., Conrad, C., Kuenzer, C., Gesell, G., \& Dech, S. (2014). Identifying Changing Snow Cover Characteristics in Central Asia between 1986 and 2014 from Remote Sensing Data. Remote Sensing, 12752-12775. doi:10.3390/rs61212752

Dozier, J. (1987). Recent research in snow hydrology. Review of Geophysics, 25(2), 153-161. doi:10.1029/RG025i002p00153

Dye, D. G. (2002). Variability and trends in the annual snow-cover cycle in Northern Hemisphere land areas, 1972-2000. Hydrological Processes, 16(15), 3065-3077. http://doi.org/10.1002/hyp.1089

Edwards, A. C., Scalenghe, R., \& Freppaz, M. (2007). Changes in the seasonal snow cover of alpine regions and its effect on soil processes: A review. Quaternary International, 162-163, 172-181. doi:10.1016/j.quaint.2006.10.027

Fernandes, R., \& G. Leblanc, S. (2005). Parametric (modified least squares) and non-parametric (Theil-Sen) linear regressions for predicting biophysical parameters in the presence of measurement errors. Remote Sensing of Environment, 95(3), 303-316. doi:10.1016/j.rse.2005.01.005 
832

833

834

835

836

837

838

839

840

841

842

843

844

845

846

847

848

849

850

851

852

853

854

855

856

857

858

859

860

861

862

863

864

865

866

867

868

Groisman, P. Y., Karl, T. R., Knight, R. W., \& Stenchikov, G. L. (1994). Changes of Snow Cover, Temperature, and Radiative Heat Balance over the Northern Hemisphere. Journal of Climate, 7(11), 1633-1656. doi:10.1175/1520-0442(1994)007<1633:COSCTA>2.0.CO;2

Handorf, D., Jaiser, R., Dethloff, K., Rinke, A., \& Cohen, J. (2015). Impacts of Arctic sea ice and continental snow cover changes on atmospheric winter teleconnections. Geophysical Research Letters, 42(7), 2367-2377. http://doi.org/10.1002/2015GL063203.

Hasanean, H. M., Almazroui, M., Jones, P. D., \& Alamoudi, a. a. (2013). Siberian high variability and its teleconnections with tropical circulations and surface air temperature over Saudi Arabia. Climate Dynamics, 41, 2003-2018. doi:10.1007/s00382-012-1657-9

Immerzeel, W. W., van Beek, L. P. H., \& Bierkens, M. F. P. (2010). Climate change will affect the Asian water towers. Science (New York, N.Y.), 328(5984), 1382-5. http://doi.org/10.1126/science.1183188

IPCC. (2014). Climate Change 2014: Impacts, Adaptation, and Vulnerability. Part B: Regional Aspects. Contribution of Working Group II to the Fifth Assessment Report of the Intergovernmental Panel on Climate Change [Barros, V.R., C.B. Field, D.J. Dokken, M.D. Mastrandrea, K.J. Mach, T.E. Bilir, M. Chatterjee, K.L. Ebi, Y.O. Estrada, R.C. Genova, B. Girma, E.S. Kissel, A.N. Levy, S. MacCracken, P.R. Mastrandrea, and L.L. White (eds.)]. Cambridge, United Kingdom and New York, NY, USA: Cambridge University Press.

Jansson, P., Hock, R., \& Schneider, T. (2003). The concept of glacier storage: a review. Journal of Hydrology, 282(1-4), 116-129. doi:10.1016/S0022-1694(03)00258-0

Jeong, J.-H., Ou, T., Linderholm, H. W., Kim, B.-M., Kim, S.-J., Kug, J.-S., \& Chen, D. (2011). Recent recovery of the Siberian High intensity. Journal of Geophysical Research: Atmospheres, 116(D23), n/a-n/a. doi:10.1029/2011JD015904

Khan, V. M., \& Holko, L. (2009). Snow cover characteristics in the Aral Sea Basin from different data sources and their relation with river runoff. Journal of Marine Systems, 76(3), 254-262. http://doi.org/10.1016/j.jmarsys.2008.03.012

Khlopenkov, K. V., \& Trishchenko, A. P. (2007). SPARC: New Cloud, Snow, and Cloud Shadow Detection Scheme for Historical 1-km AVHHR Data over Canada. Journal of Atmospheric and Oceanic Technology, 24(3), 322-343. doi:10.1175/JTECH1987.1

Kotlyakov, V. M. (Ed.). (1997). World Atlas of Snow and Ice Resources. Moscow.

Krenke, A. (1998). Former Soviet Union hydrological snow surveys, 1966-1996 Version 1, Edited by NSIDC. Boulder, Colorado USA. NSIDC: National Snow and Ice Data Center. Retrieved September 1, 2009, from http://nsidc.org/data/g01170.html. doi: http://dx.doi.org/10.7265/N58C9T60

Lattin, J., Carroll, D., \& Green, P. (2002). Analyzing Multivariate Data. Duxbury Press; 1 edition. Retrieved from http://www.amazon.com/Analyzing-Multivariate-CD-ROM-DuxburyApplied/dp/0534349749/ref=sr_1_1?s=books\&ie=UTF8\&qid=1323192580\&sr=1-1 
869

870

871

872

873

874

875

876

877

878

879

880

881

882

883

884

885

886

887

888

889

890

891

892

893

894

895

896

897

898

899

900

901

902

903

Li, F., \& Wang, H. (2014). Autumn Eurasian snow depth, autumn Arctic sea ice cover and East Asian winter monsoon. International Journal of Climatology, 34(13), 3616-3625. http://doi.org/10.1002/joc.3936

Liang, T., Huang, X., Wu, C., Liu, X., Li, W., Guo, Z., \& Ren, J. (2008). An application of MODIS data to snow cover monitoring in a pastoral area: A case study in Northern Xinjiang, China. Remote Sensing of Environment, 112(4), 1514-1526. doi:10.1016/j.rse.2007.06.001

Lioubimtseva, E., \& Henebry, G. M. (2009). Climate and environmental change in arid Central Asia: Impacts, vulnerability, and adaptations. Journal of Arid Environments, 73(11), 963-977. doi:10.1016/j.jaridenv.2009.04.022

Lydolph, P. E. (1977). Climates of the Soviet Union. Amsterdam [etc.]: Elsevier.

Mannig, B., Müller, M., Starke, E., Merkenschlager, C., Mao, W., Zhi, X., ... Paeth, H. (2013). Dynamical downscaling of climate change in Central Asia. Global and Planetary Change, 110, 26-39. doi:10.1016/j.gloplacha.2013.05.008

Mölg, T., Maussion, F., \& Scherer, D. (2013). Mid-latitude westerlies as a driver of glacier variability in monsoonal High Asia. Nature Climate Change, 4(1), 68-73. doi:10.1038/nclimate2055

Muggeo, V. M. R. (2008). segmented: An R package to Fit Regression Models with Broken-Line Relationships. $R$ News, 8(May), 20-25. doi:10.1159/000323281

NOAA. (1998). NOAA Polar Orbiter Data User's Guide. Retrieved September 1, 2009, from http://www2.ncdc.noaa.gov/docs/podug/index.htm

NOAA. (2007). NOAA KLM USER'S GUIDE. Retrieved September 1, 2009, from http://www.ncdc.noaa.gov/oa/pod-guide/ncdc/docs/klm/index.htm

Ososkova, T., Gorelkin, N., \& Chub, V. (2000). Water resources of central Asia and adaptation measures for climate change. Environmental Monitoring and Assessment, Retrieved from http://link.springer.com/article/10.1023/A:1006394808699

Panagiotopoulos, F., Shahgedanova, M., Hannachi, A., \& Stephenson, D. B. (2005). Observed trends and teleconnections of the Siberian high: A recently declining center of action. Journal of Climate, 18(9), 1411-1422. http://doi.org/10.1175/JCLI3352.1

Parajka, J., Pepe, M., Rampini, A., Rossi, S., \& Blöschl, G. (2010). A regional snow-line method for estimating snow cover from MODIS during cloud cover. Journal of Hydrology, 381(3-4), 203212. http://doi.org/10.1016/j.jhydrol.2009.11.042

Peng, S., Piao, S., Ciais, P., Friedlingstein, P., Zhou, L., \& Wang, T. (2013). Change in snow phenology and its potential feedback to temperature in the Northern Hemisphere over the last three decades. Environmental Research Letters, 8(1), 014008. doi:10.1088/1748$9326 / 8 / 1 / 014008$ 
904

905

906

907

908

909

910

911

912

913

914

915

916

917

918

919

920

921

922

923

924

925

926

927

928

929

930

931

932

933

934

935

936

937

938

Pohl, E., Knoche, M., Gloaguen, R., Andermann, C., \& Krause, P. (2014). The hydrological cycle in the high Pamir Mountains: how temperature and seasonal precipitation distribution influence stream flow in the Gunt catchment, Tajikistan. Earth Surface Dynamics Discussions, 2(2), 1155-1215. http://doi.org/10.5194/esurfd-2-1155-2014

R Core Team (2015). R: A language and environment for statistical computing. R Foundation for Statistical Computing, Vienna, Austria. URL http://www.R-project.org/.

Reuter, H. I., Nelson, A., \& Jarvis, A. (2007). An evaluation of void-filling interpolation methods for SRTM data. International Journal of Geographical Information Science, 21(9), 983-1008. http://doi.org/10.1080/13658810601169899

Robinson, D. A., Scharfen, G., Serreze, M. C. M., Kukla, G., \& Barry, R. G. (1986). Snow melt and surface albedo in the arctic basin. Geophysical Research Letters, 13(9), 945-948. http://doi.org/10.1029/GL013i009p00945

Robinson, D. a., Dewey, K. F., \& Heim, R. R. (1993). Global Snow Cover Monitoring: An Update. Bulletin of the American Meteorological Society. http://doi.org/10.1175/15200477(1993)074<1689:GSCMAU>2.0.CO;2

Rototaeva, O.V. 1983. Glaciologicheskoe raionirovanie Pamira (The Pamir glaciological zoning). Data of Glaciological Studies, V. 46, M., pp. 39-51(in Russ.)

Schiemann, R., Glazirina, M. G., \& Schär, C. (2007). On the relationship between the Indian summer monsoon and river flow in the Aral Sea basin. Geophysical Research Letters, 34(5), L05706. http://doi.org/10.1029/2006GL028926

Sen, P. K. (1968). Estimates of the regression coefficient based on Kendall's tau. Journal of the American Statistical Association, 63, 1379 - 1389.

Severskiy, I. V., \& Severskiy, E. V. (2003). The influence of local factors on snow cover and seasonal ground freezing in the Tien Shan. In Phillips, Springman, \& Arenson (Eds.), Permafrost (pp. 1023 - 1028).

Siegfried, T., Bernauer, T., Guiennet, R., Sellars, S., Robertson, A. W., Mankin, J., ... Yakovlev, A. (2012). Will climate change exacerbate water stress in Central Asia? Climatic Change, 112, 881-899. doi:10.1007/s10584-011-0253-z

Singh, V. P. (2010). Snow and Glacier Hydrology (p. 756). Springer; Softcover reprint of hardcover 1st ed. 2001 edition. Retrieved from http://www.amazon.com/Glacier-Hydrology-ScienceTechnology-Library/dp/9048156351/ref=sr 1 1 ?s=books\&ie=UTF8\&qid=1323193452\&sr=1$\underline{1}$

Sorg, A., Bolch, T., Stoffel, M., Solomina, O., \& Beniston, M. (2012). Climate change impacts on glaciers and runoff in Tien Shan (Central Asia). Nature Climate Change, 2(10), 725-731. http://doi.org/10.1038/nclimate1592 
939

940

942

943

944
Surazakov, a B., Aizen, V. B., Aizen, E. M., \& Nikitin, S. a. (2007). Glacier changes in the Siberian Altai Mountains, Ob river basin, (1952-2006) estimated with high resolution imagery. Environmental Research Letters, 2(4), 045017. http://doi.org/10.1088/1748-9326/2/4/045017

Theil, H. (1950). A rank-invariant method of linear and polynomial regresion analysis, I. Nederlands Akad. Wetensch. Proc., 53, 386 - 392.

Wang, X., \& Xie, H. (2009). New methods for studying the spatiotemporal variation of snow cover based on combination products of MODIS Terra and Aqua. Journal of Hydrology, 371(1-4), 192-200. doi:10.1016/j.jhydrol.2009.03.028

Wang, X., Xie, H., \& Liang, T. (2009). Comparison and validation of MODIS standard and new combination of Terra and Aqua snow cover products in northern Xinjiang, China. Hydrological Processes, 429(October 2008), 419-429. doi:10.1002/hyp

You, Q., Fraedrich, K., Ren, G., Ye, B., Meng, X., \& Kang, S. (2012). Inconsistencies of precipitation in the eastern and central Tibetan Plateau between surface adjusted data and reanalysis. Theoretical and Applied Climatology, 109(3-4), 485-496. http://doi.org/10.1007/s00704-012-0594-1

Zhou, H., Aizen, E., \& Aizen, V. (2013). Deriving long term snow cover extent dataset from AVHRR and MODIS data: Central Asia case study. Remote Sensing of Environment, 136, 146162. doi:10.1016/j.rse.2013.04.015 


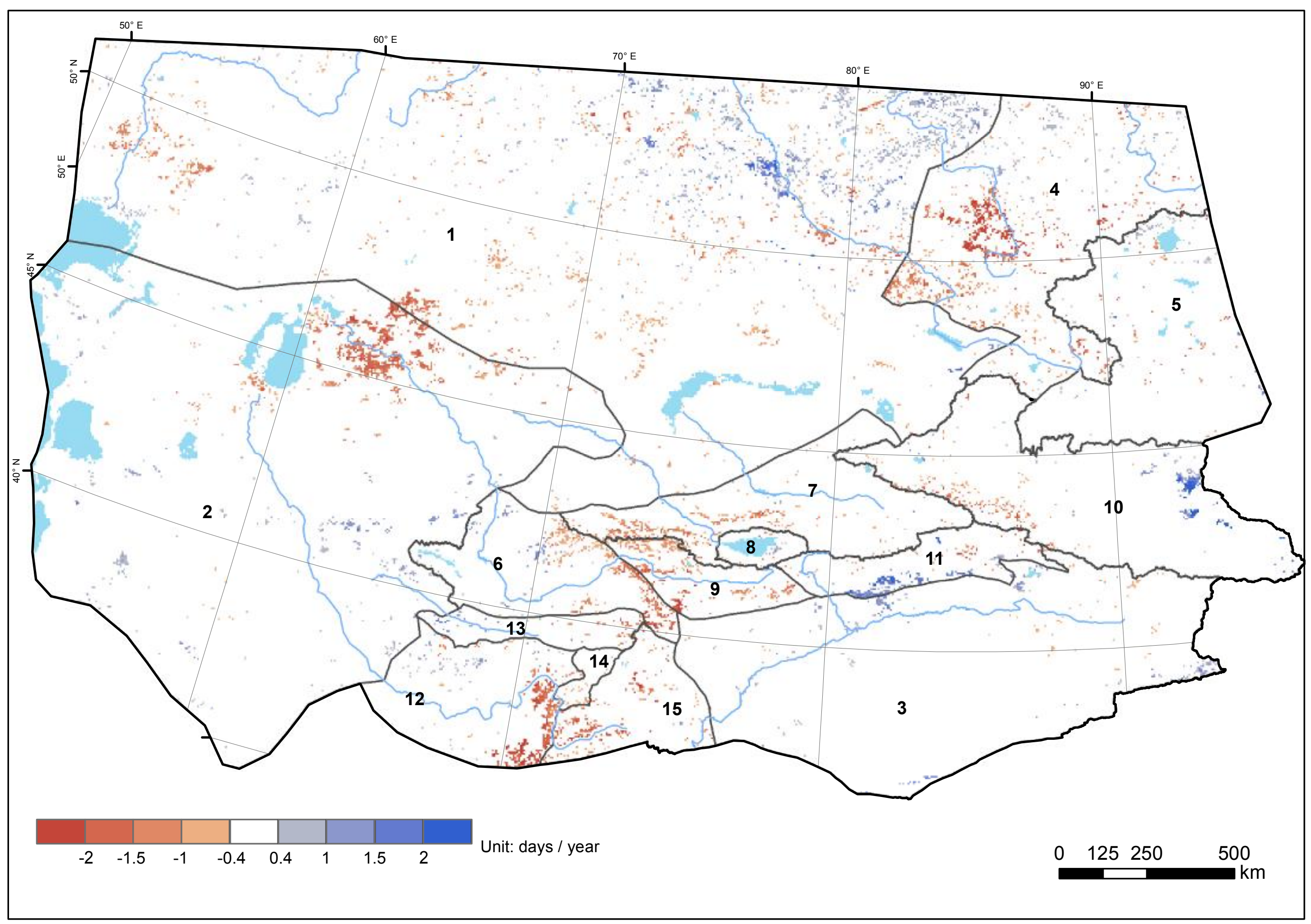




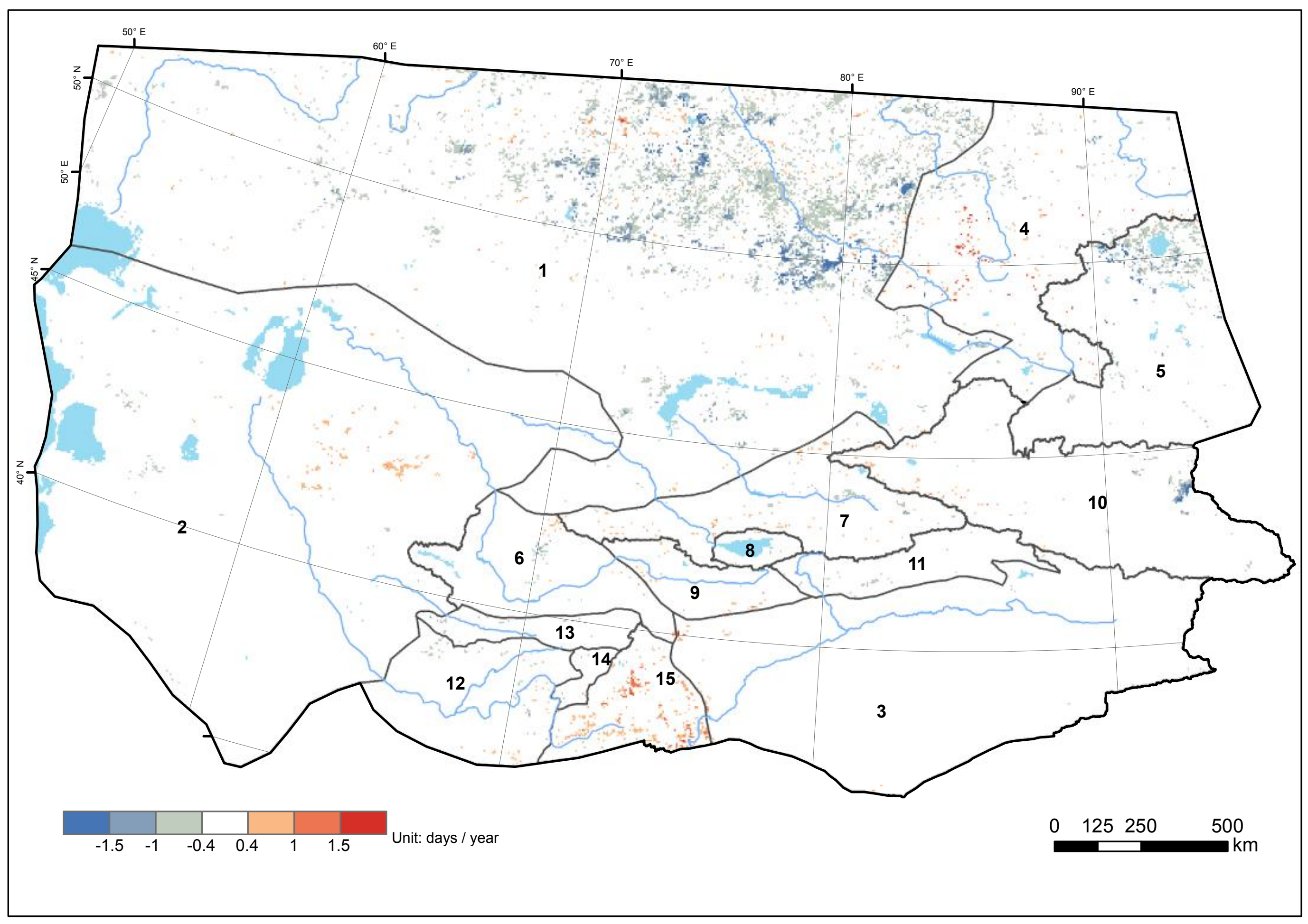




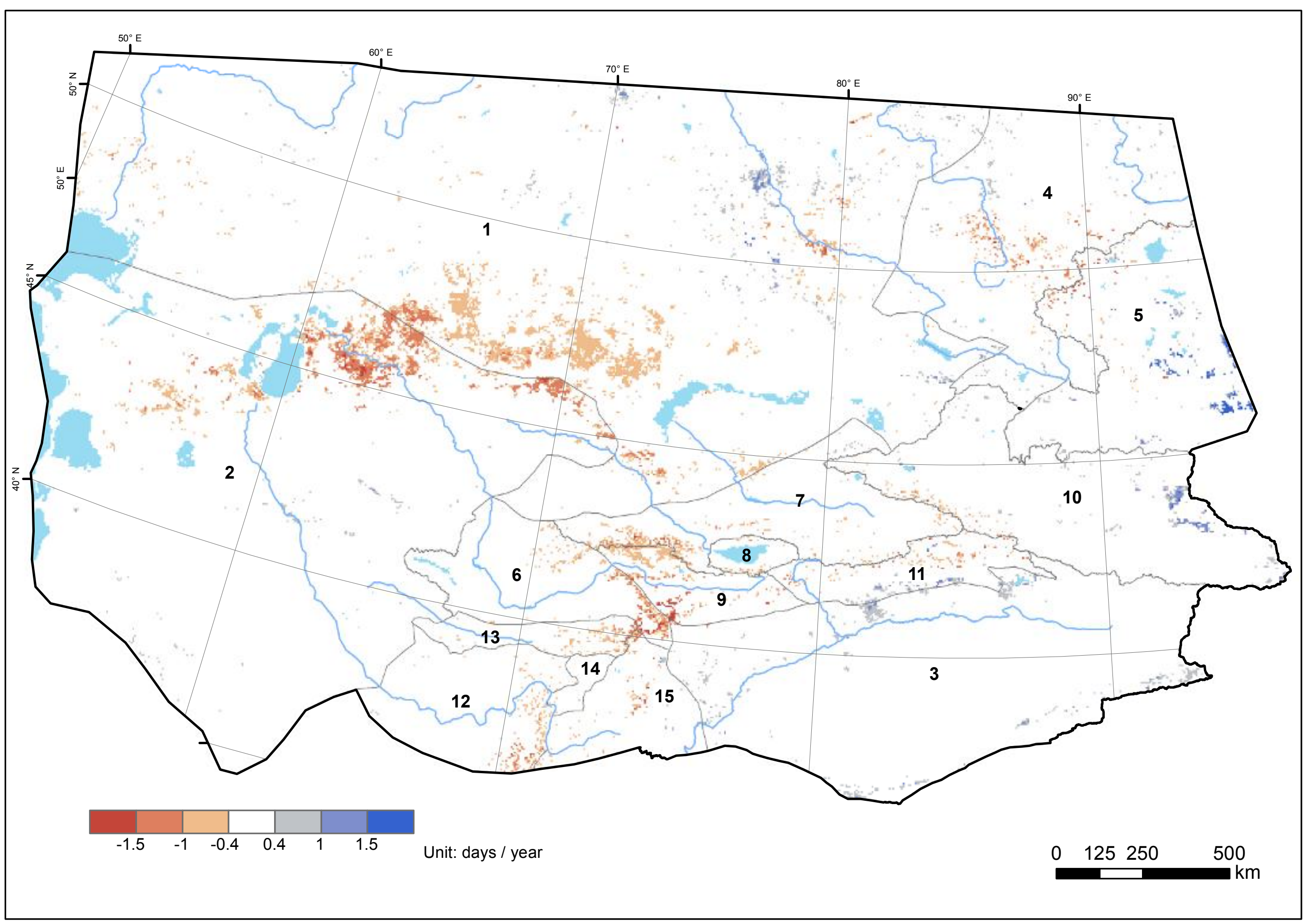




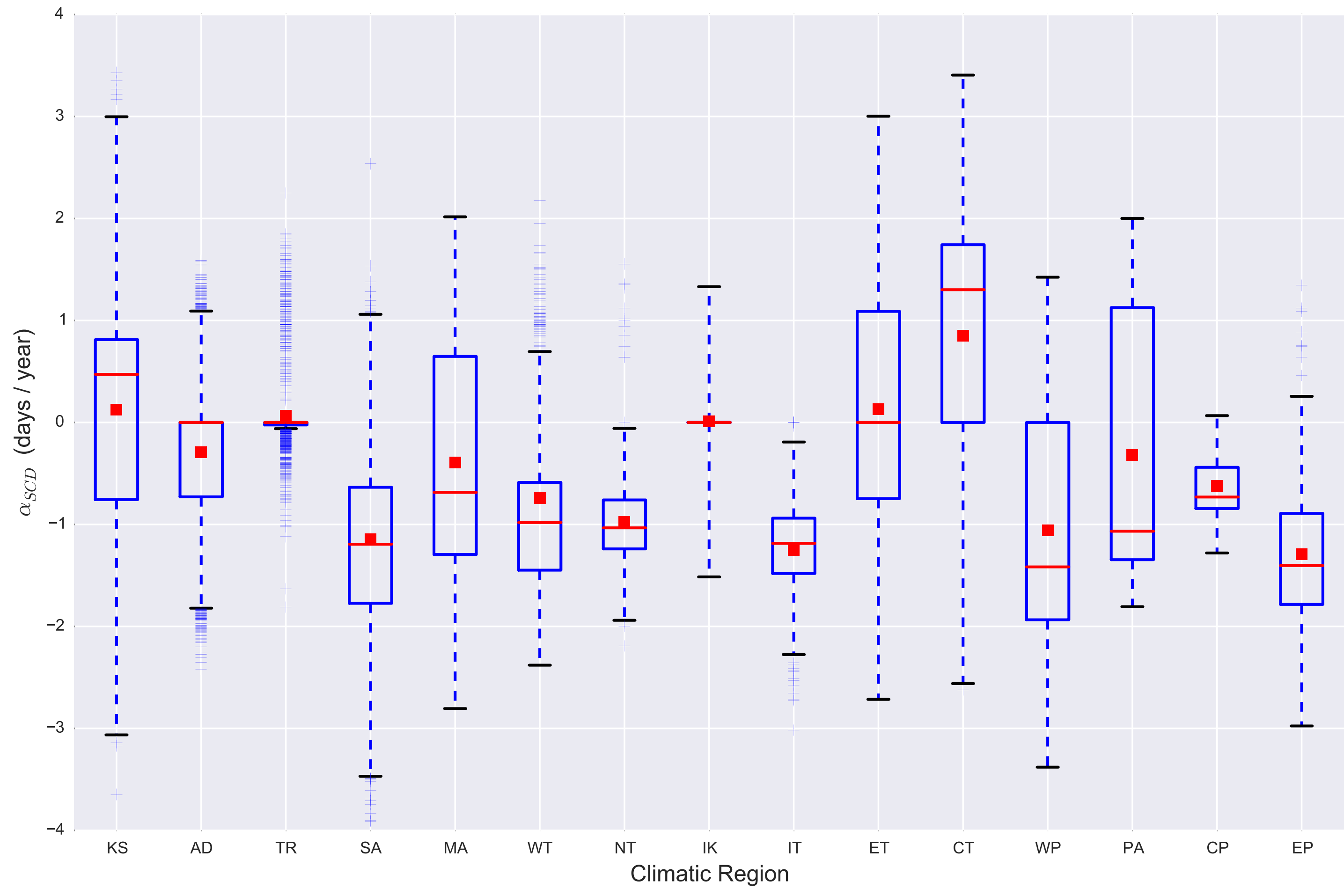


$<1000$
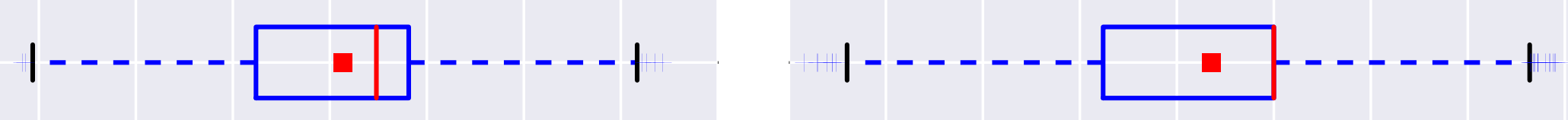

$+n+\cdots$
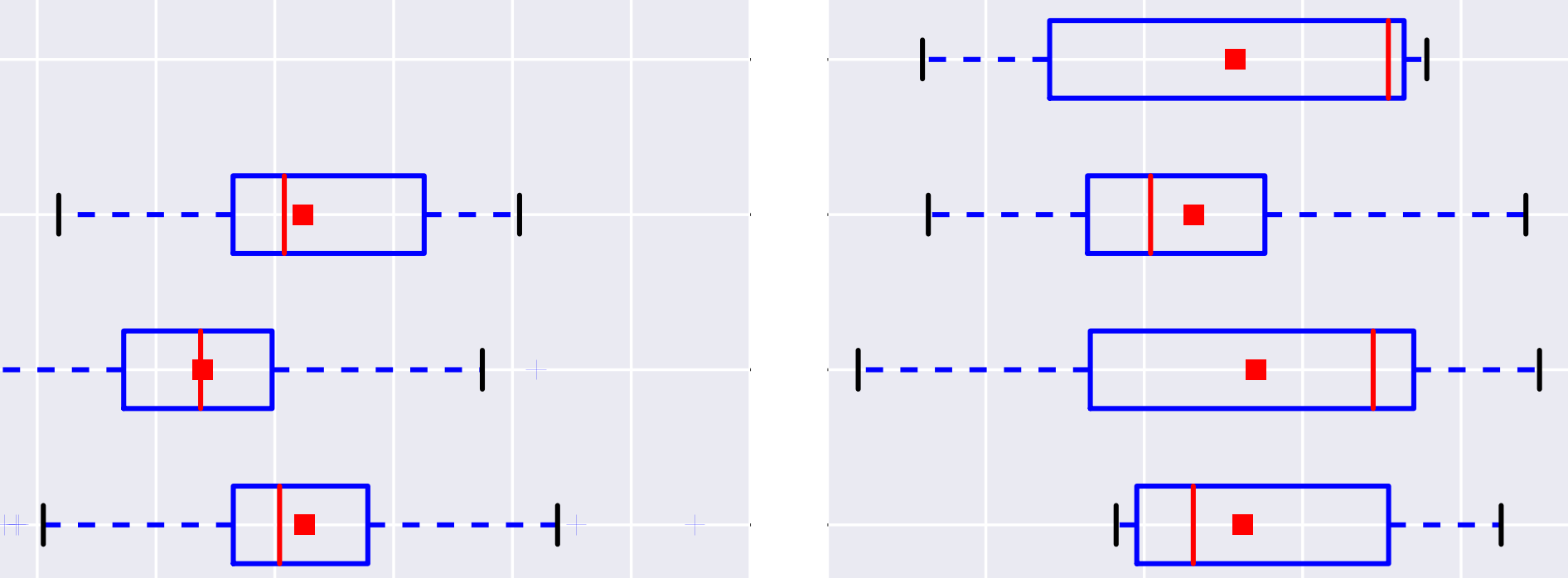

$<1000$

$2000-3000$

$1000-2000$

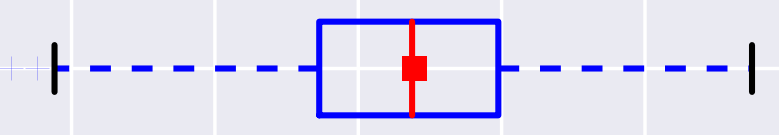

7) Northern Tien Shan

$>4000$

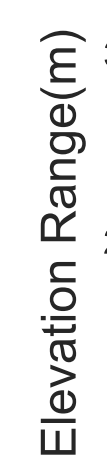

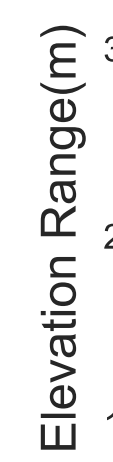

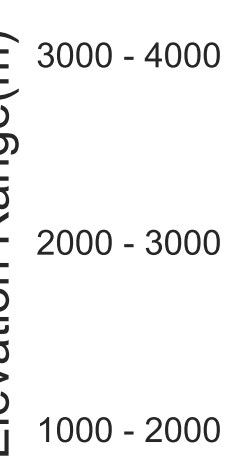

$$
\text { 1- - - }
$$$$
1---\square-1
$$$$
1--\square-1
$$

$<1000$

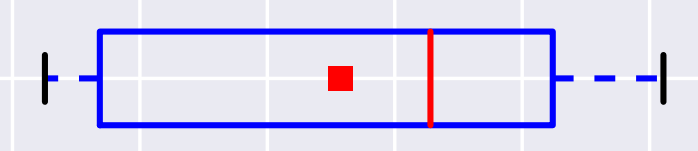

$\begin{array}{lllllllllll}-2.5 & -2.0 & -1.5 & -1.0 & -0.5 & 0.0 & 0.5 & 1.0 & 1.5 & 2.0 & -2.0\end{array}$ 10) Eastern Tien Shan

$>4000$

$\amalg$

$3000-4000 \quad 1--\square-1$

$2000-3000 \quad 1---\square \square---1$

$1000-2000$

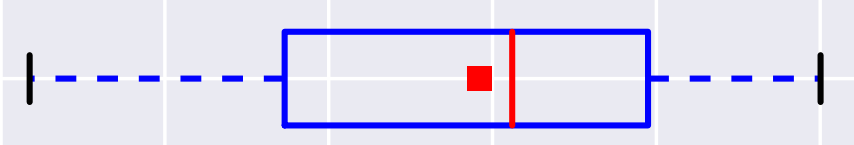

$<1000$

㠹

13) Pamiro-Alai

$>4000$

$3000-4000$ ト-

$2000-3000$

$1000-2000$

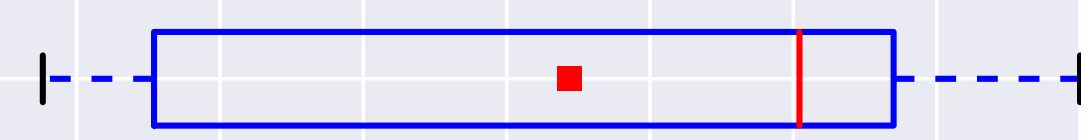

$1-\square-1$

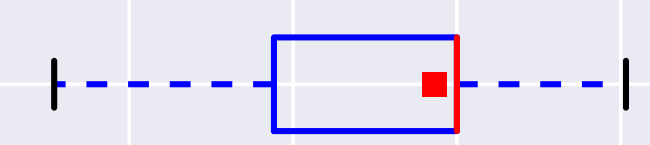

$$
1--\square-1
$$

地一

14) Central Pamir

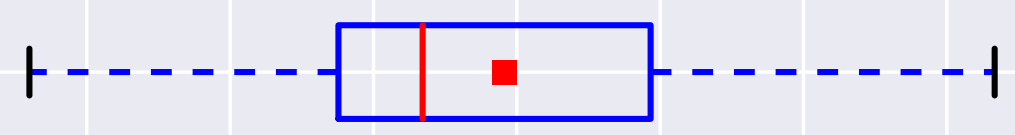

$1-4-1$<smiles></smiles>

时

$$
\begin{aligned}
& 1--\square--1 \\
& \text { ト-- } \square-1
\end{aligned}
$$
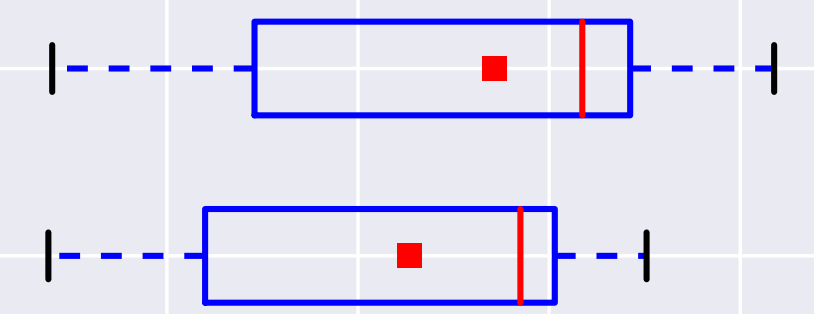

9) Inner Tien Shan

$$
1-\square-1
$$

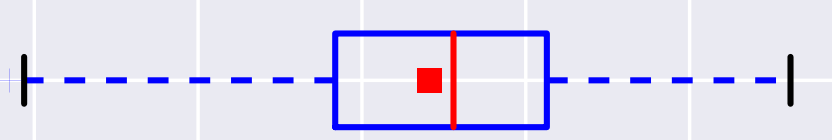

$1--\square-1$ 
Air Temperature $\left({ }^{\circ} \mathrm{C}\right)$
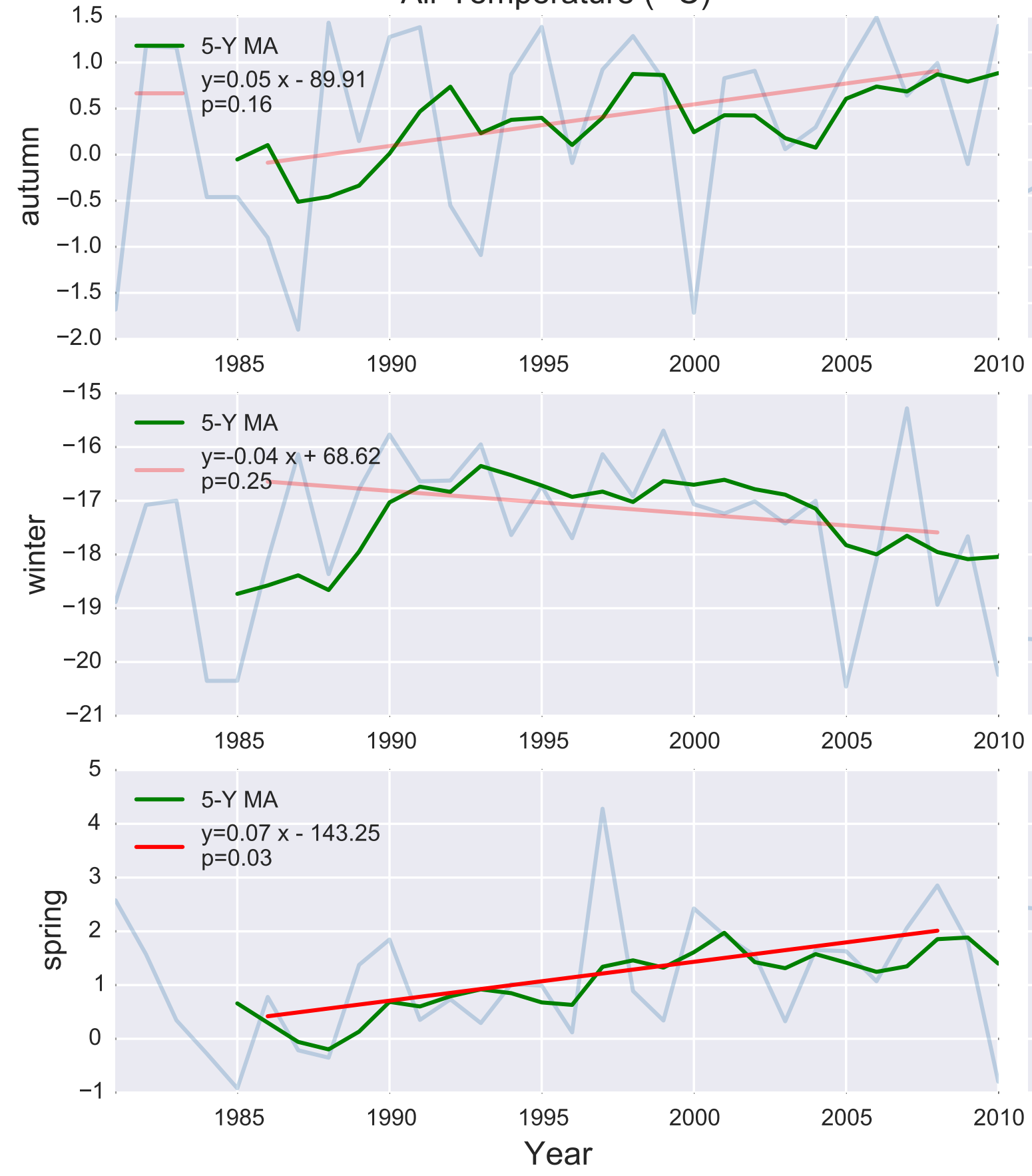

Precipitation (mm)

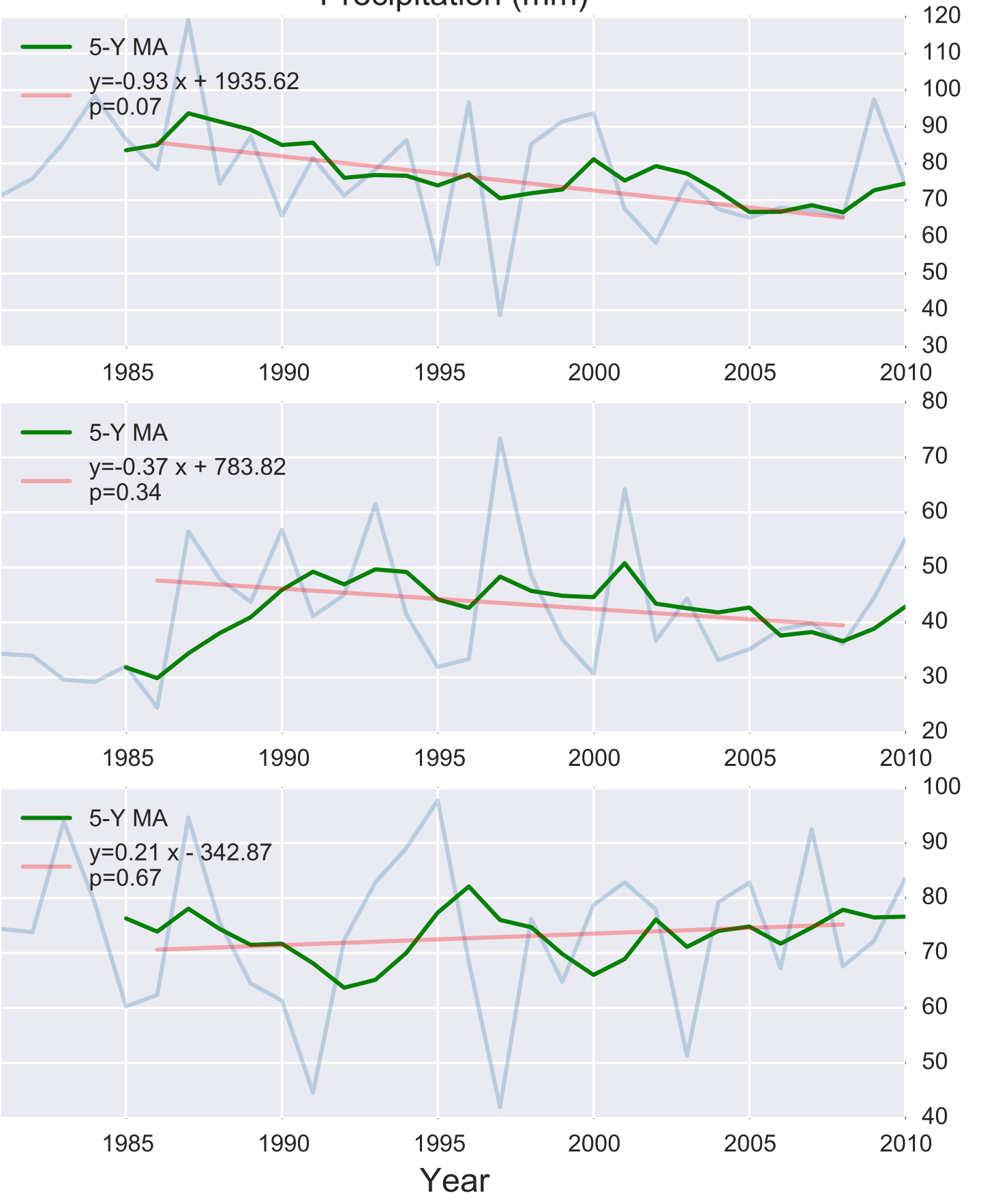


Air Temperature $\left({ }^{\circ} \mathrm{C}\right)$

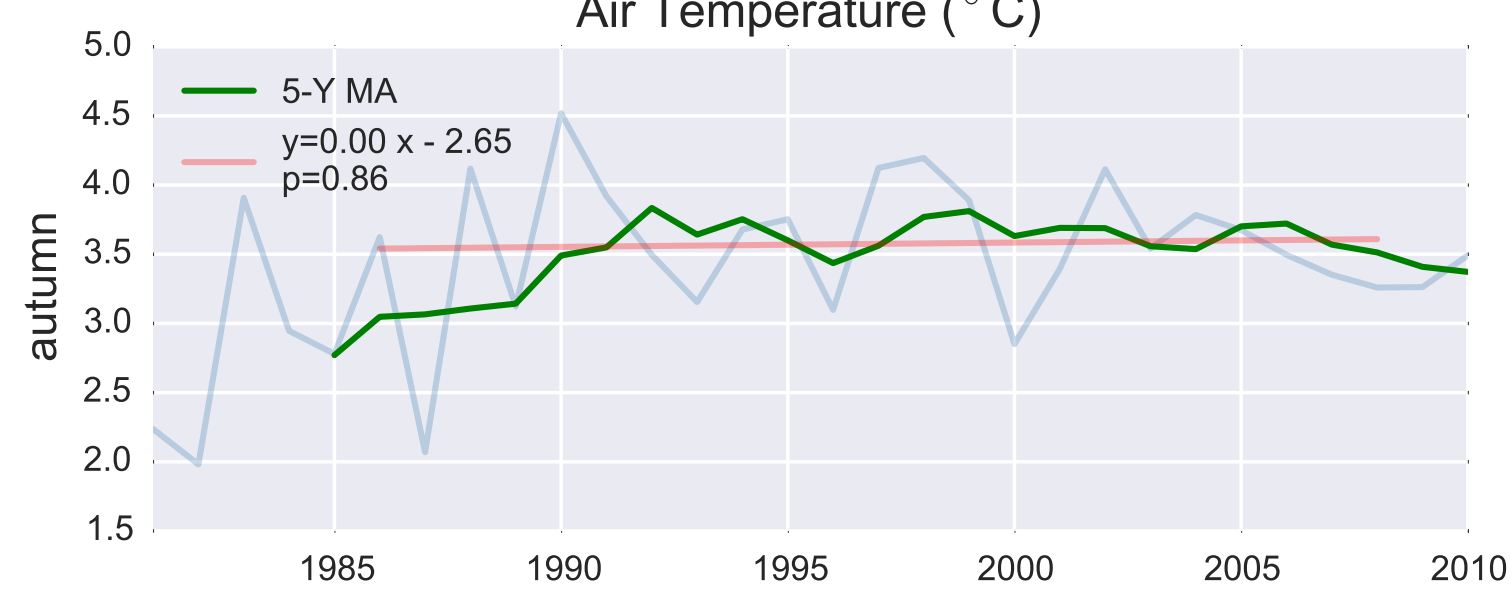

Precipitation $(\mathrm{mm})$

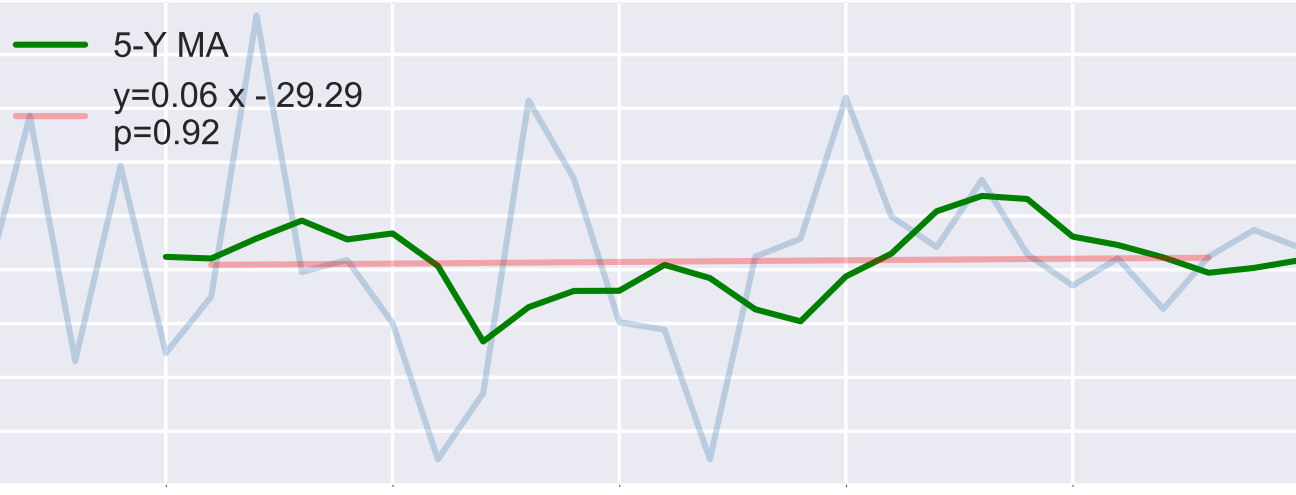

140
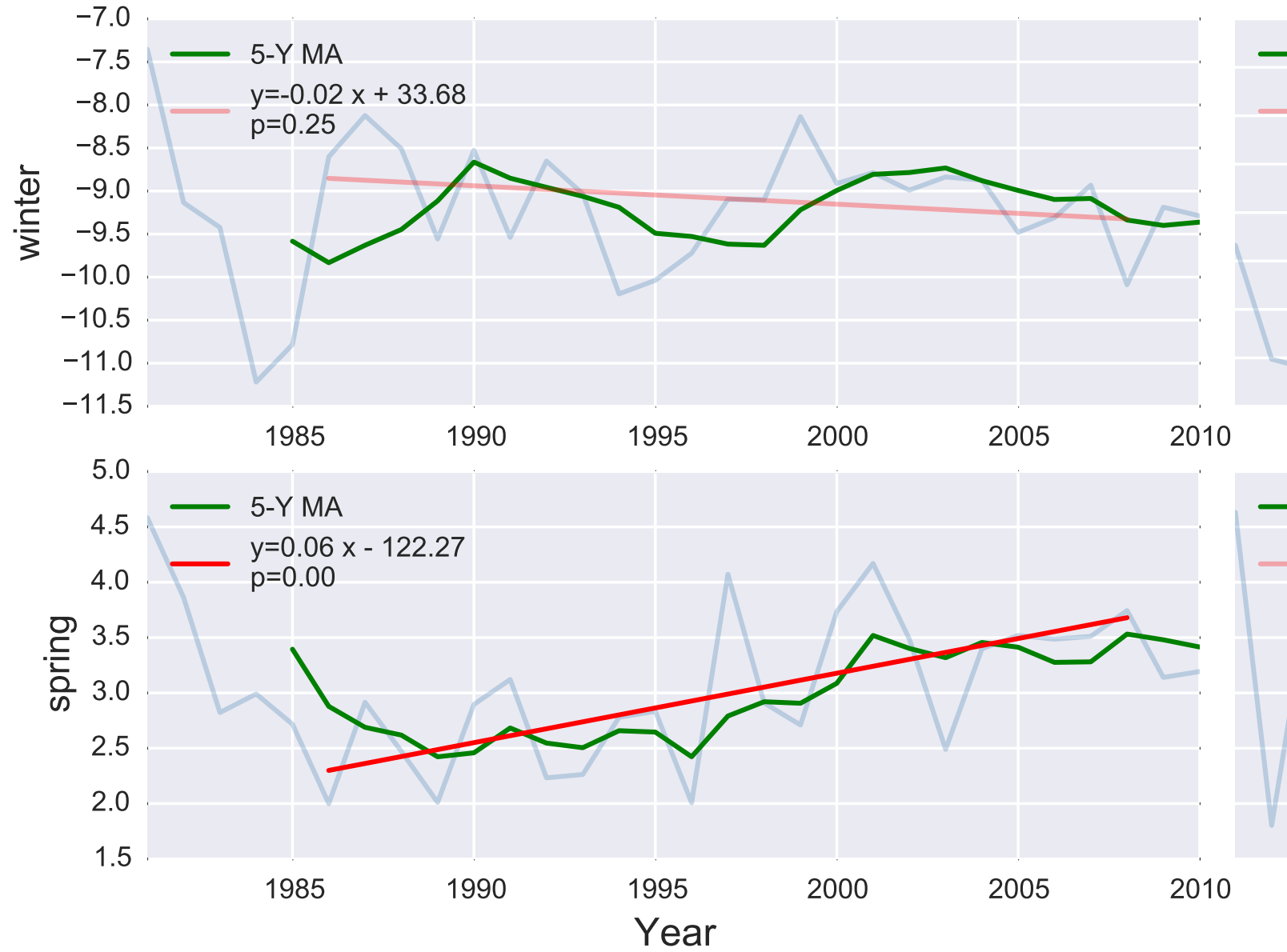

1985

1990

1995

2000

2005

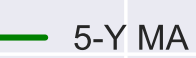

$y=-0.15 x+387.29$ $p=0.72$

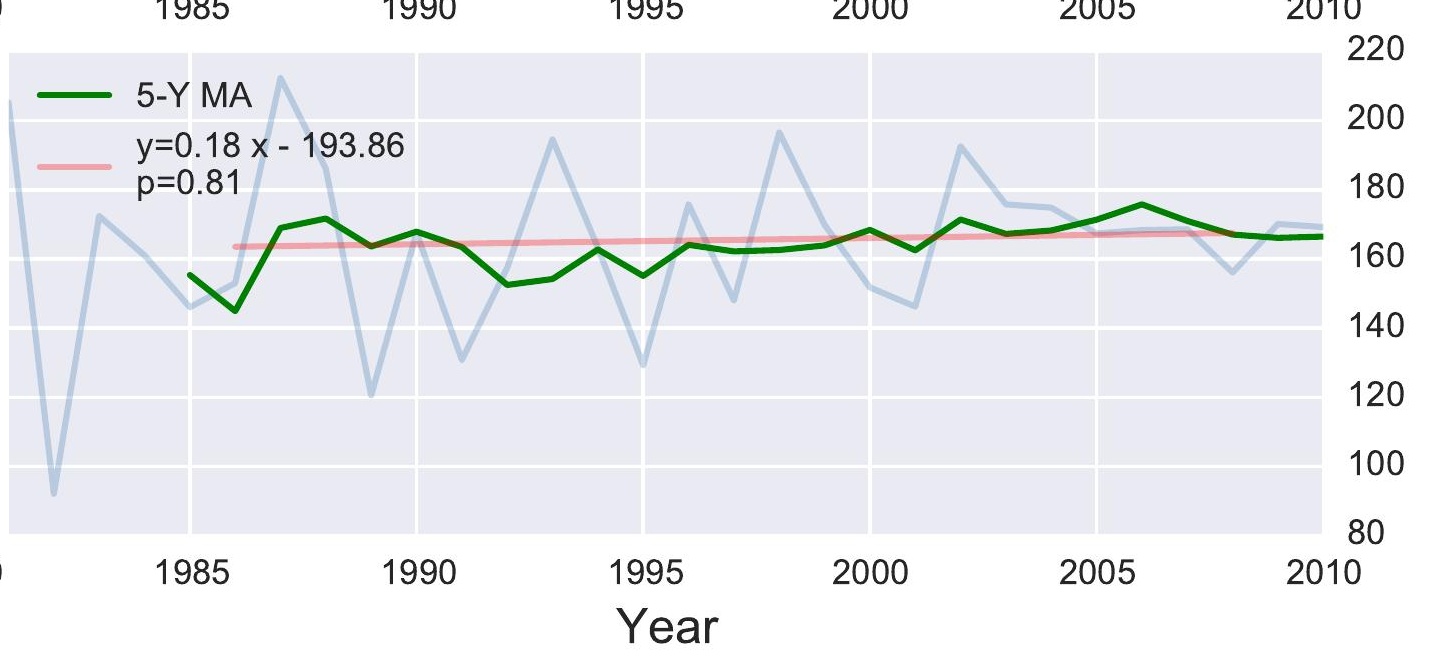




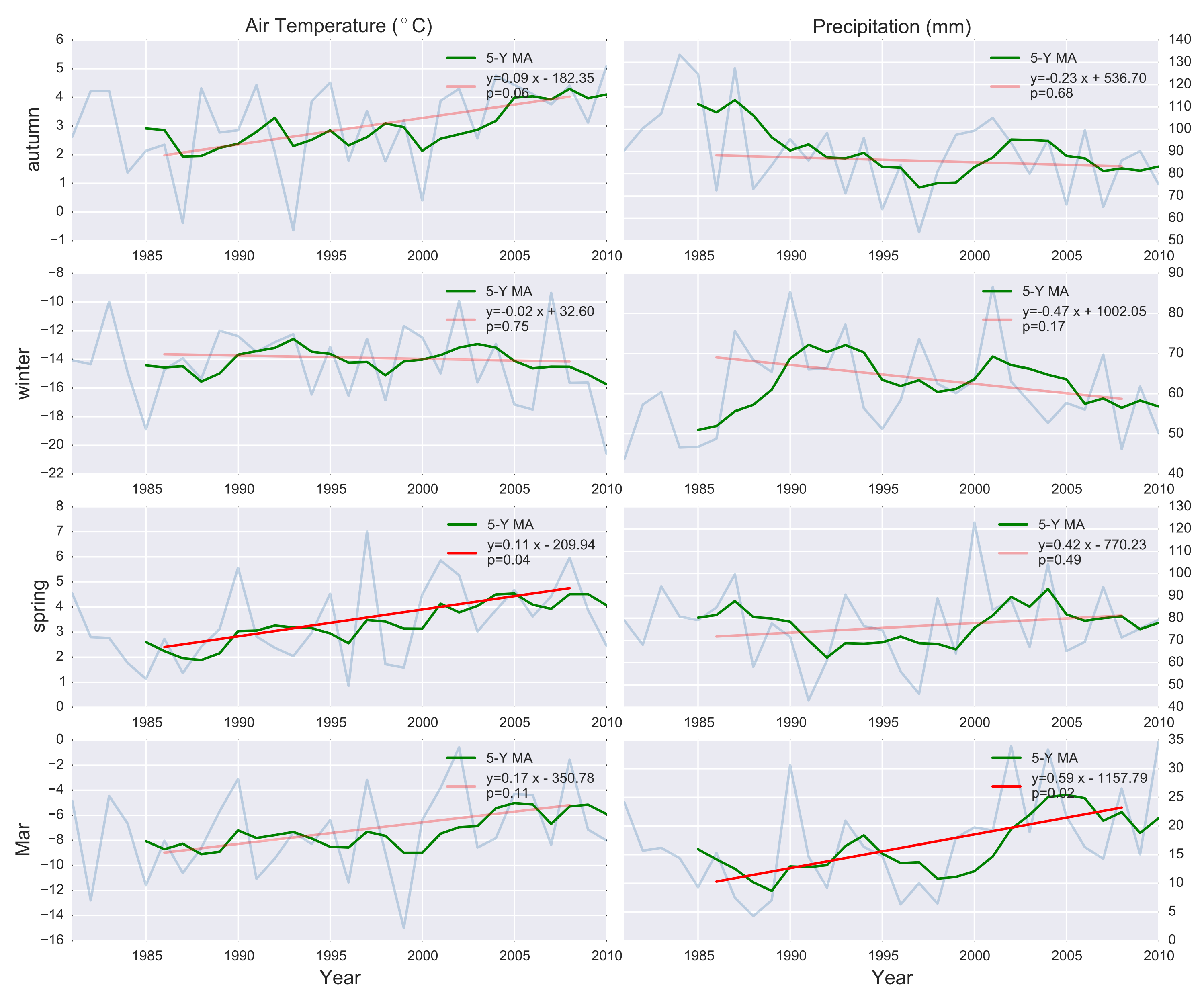




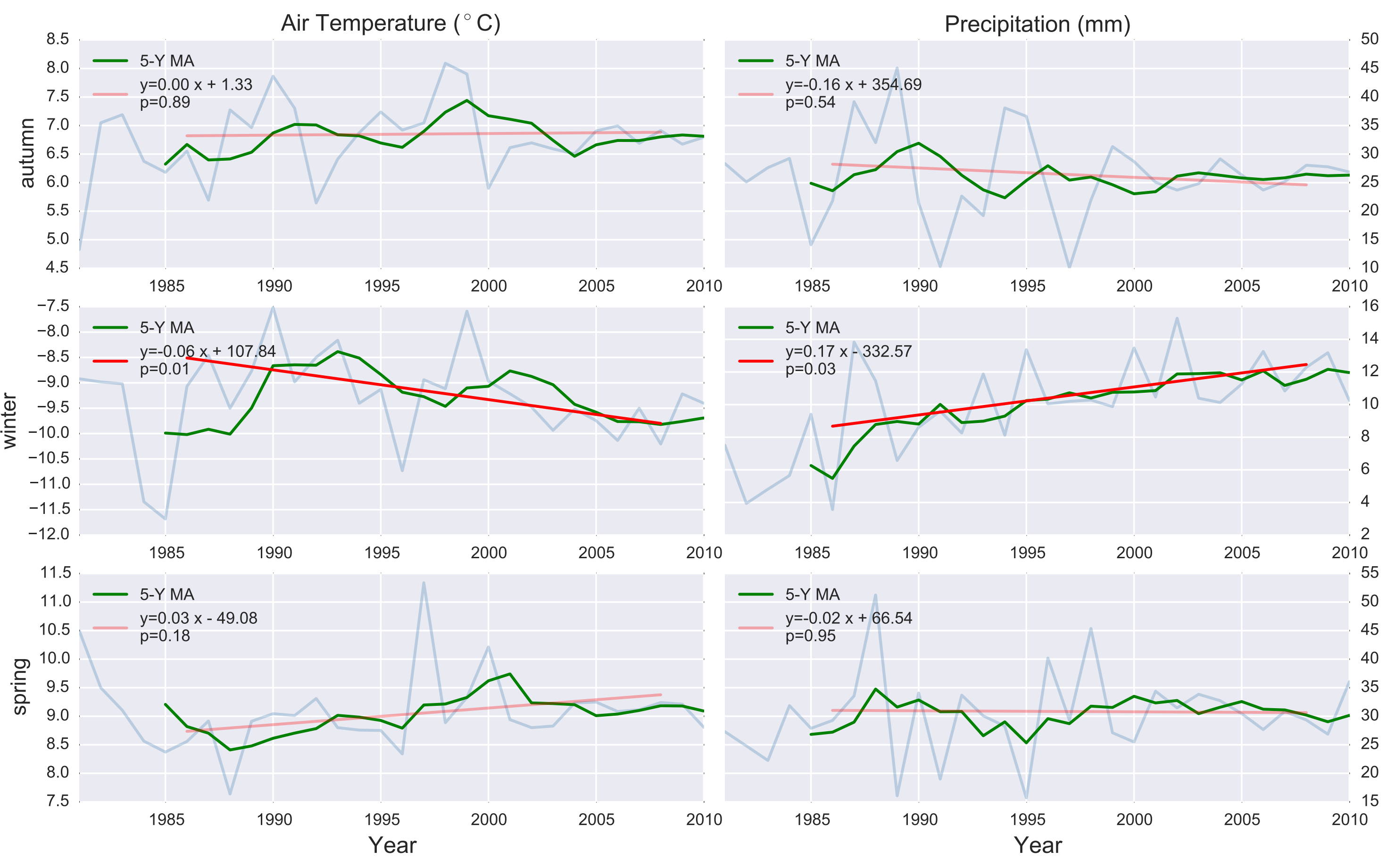




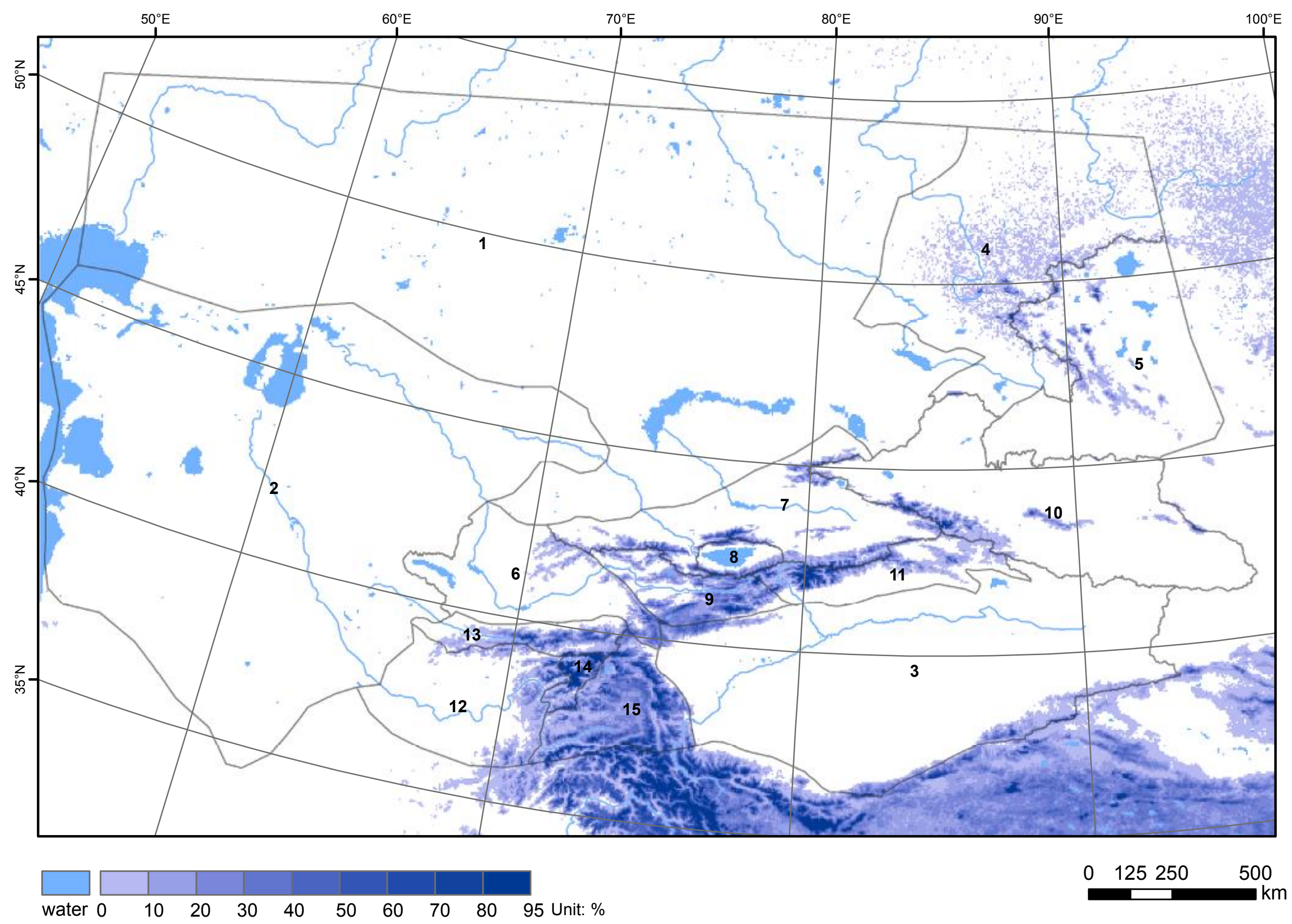




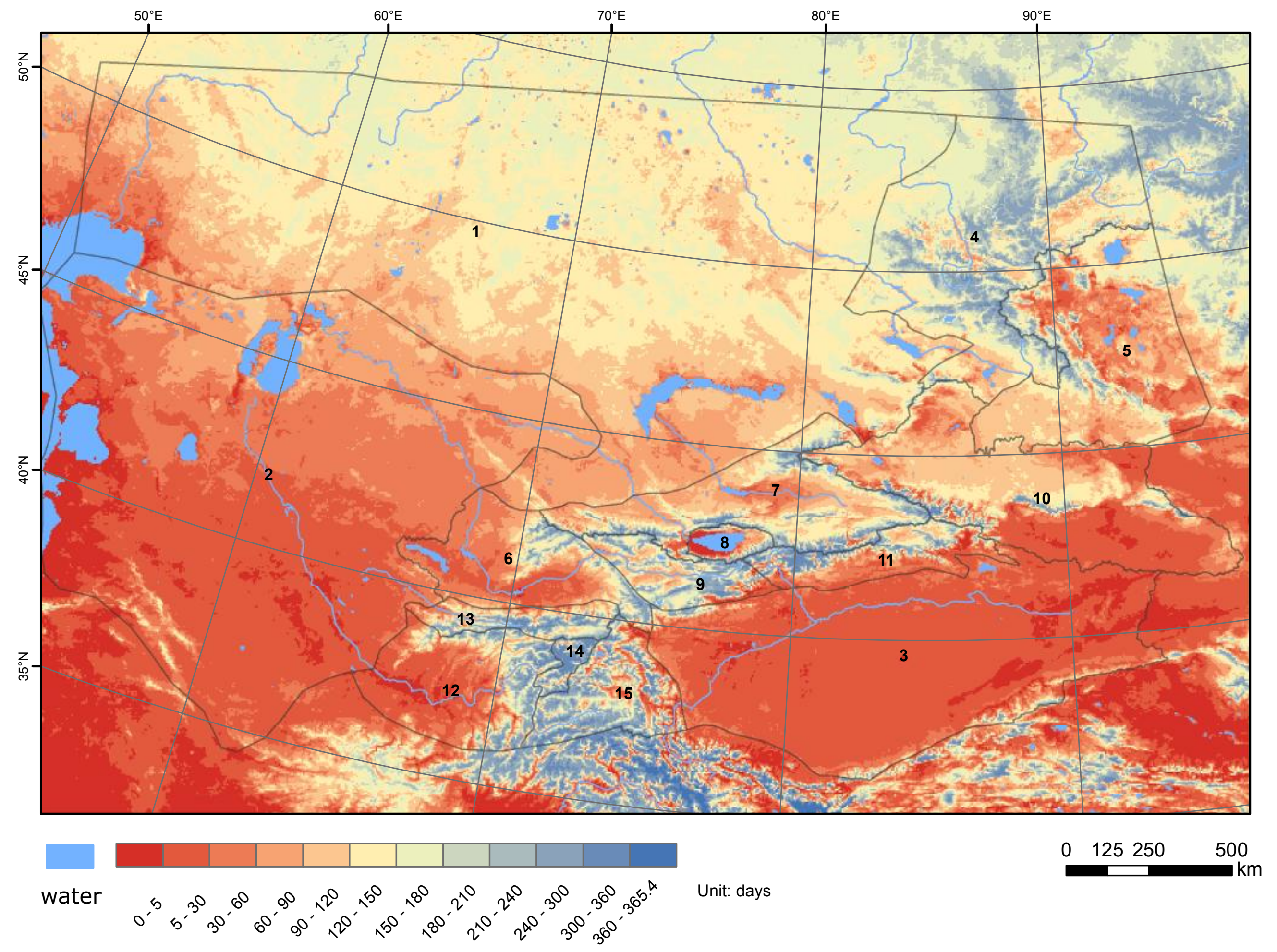



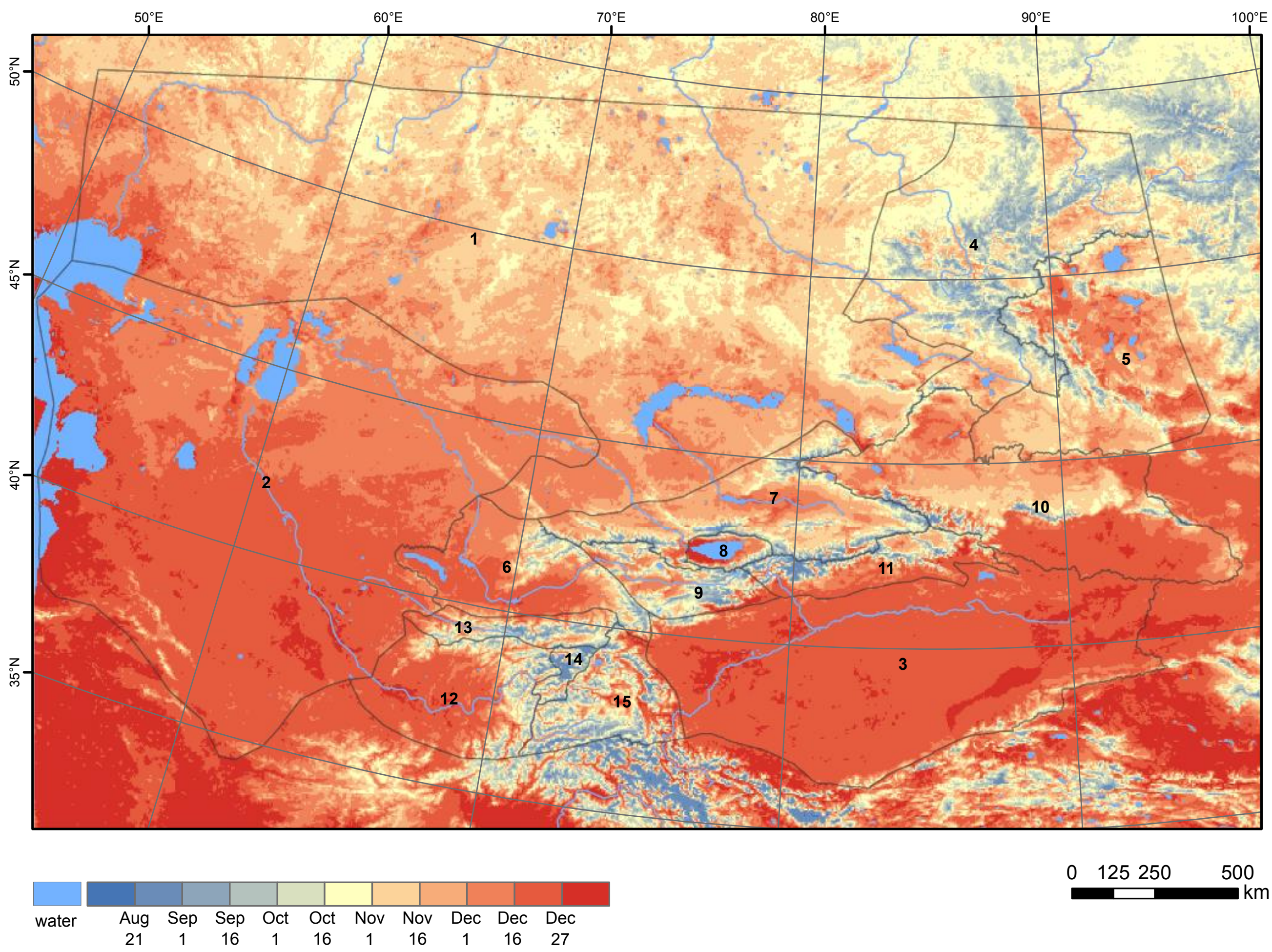


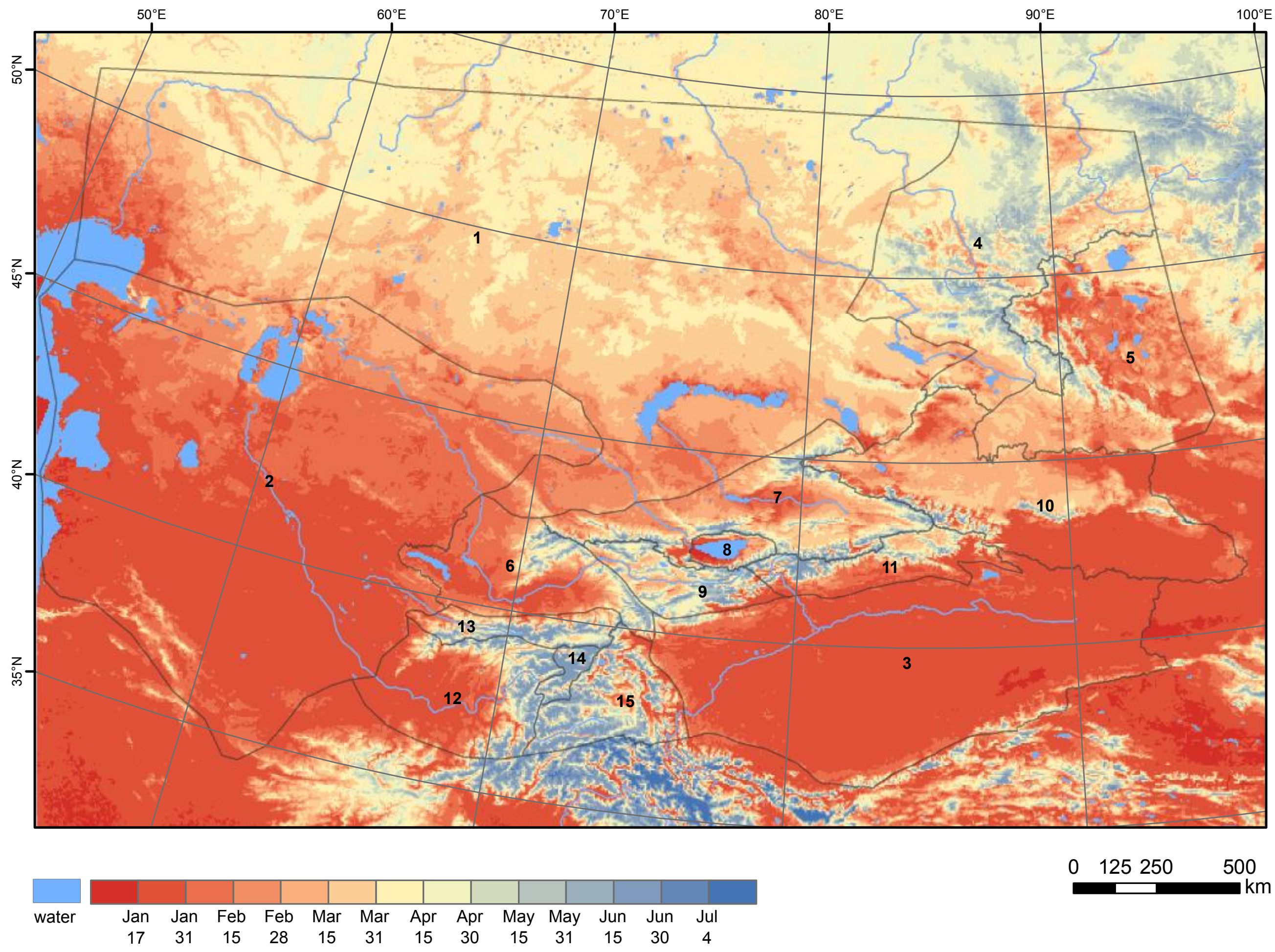




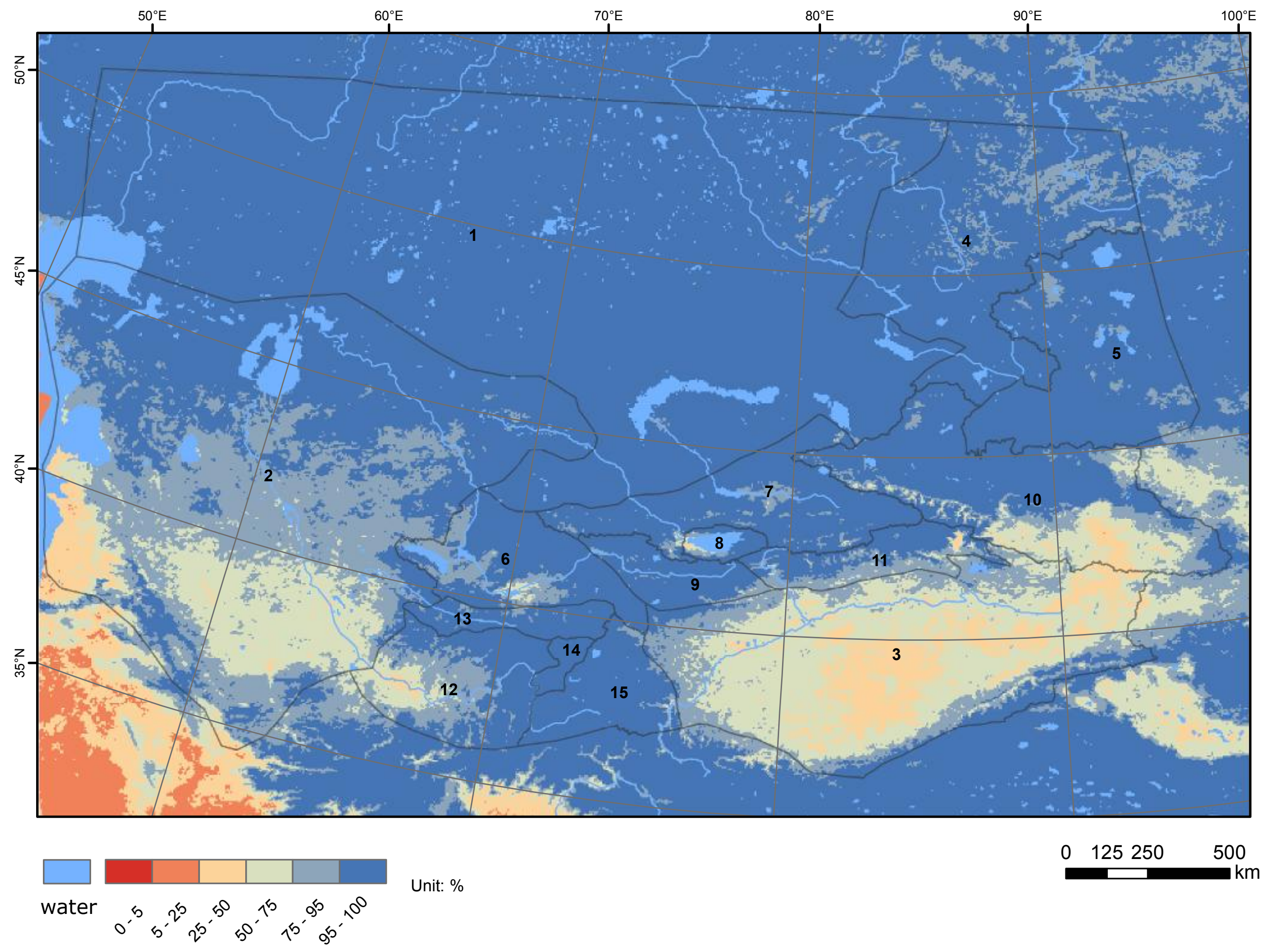




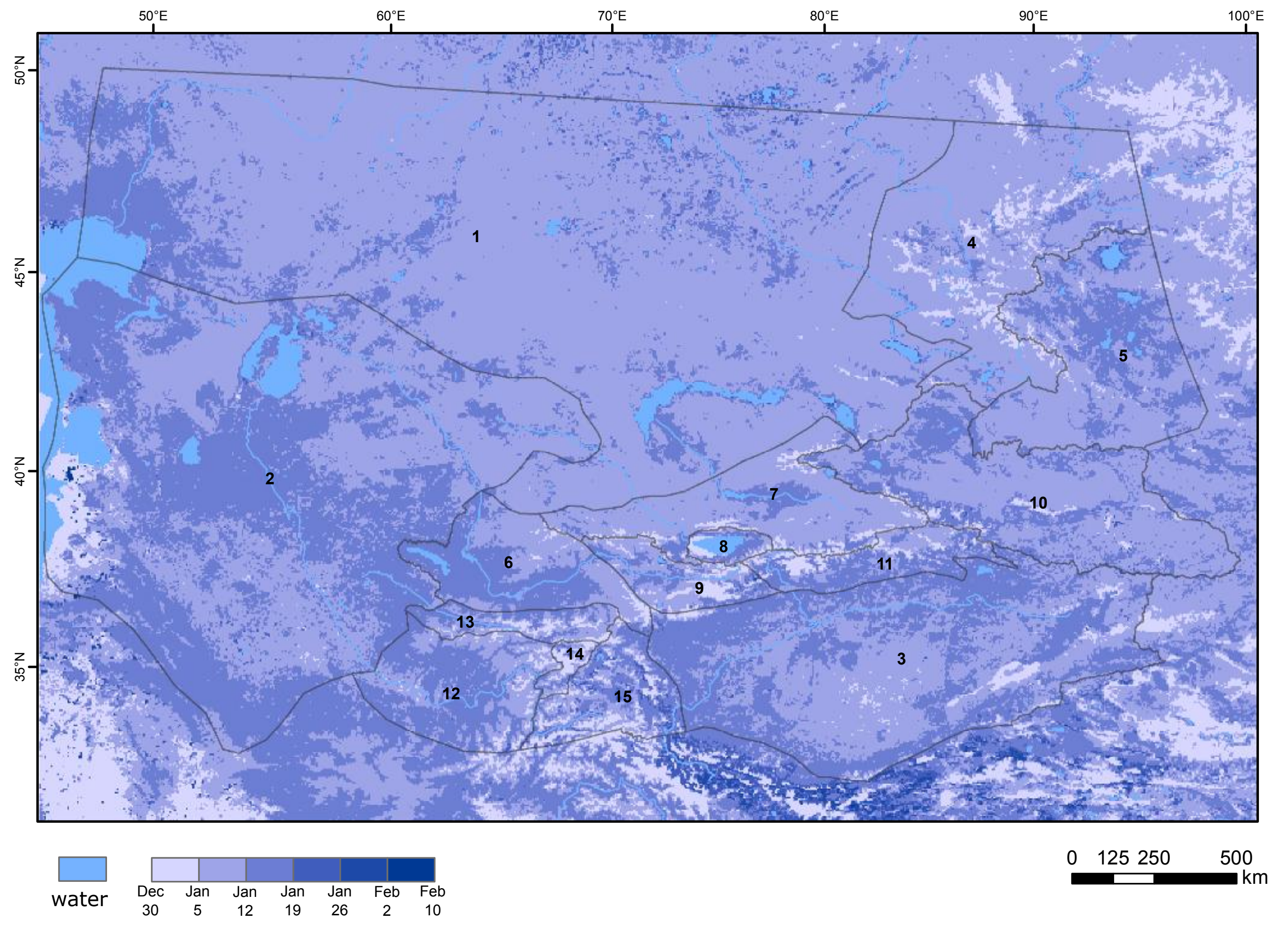



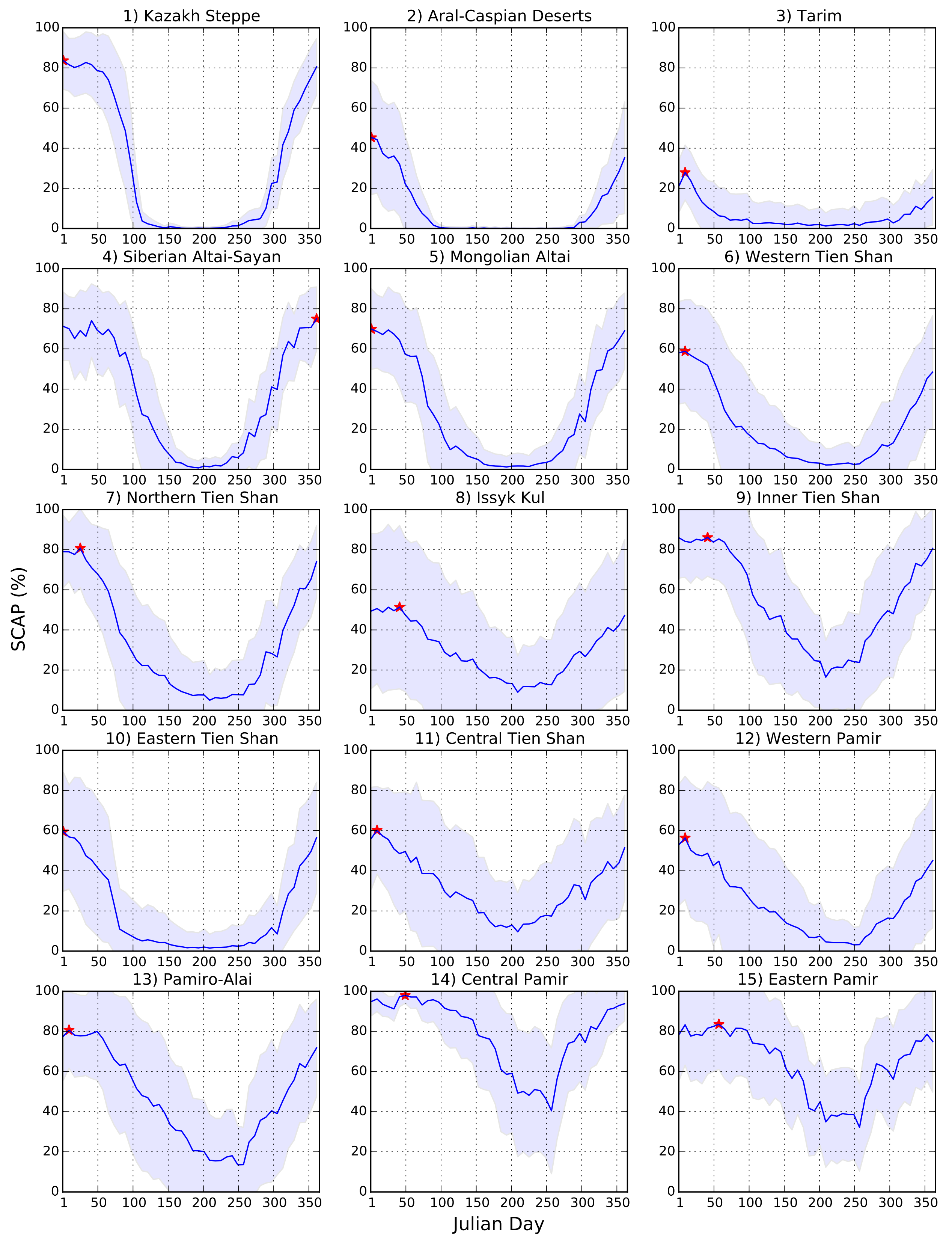


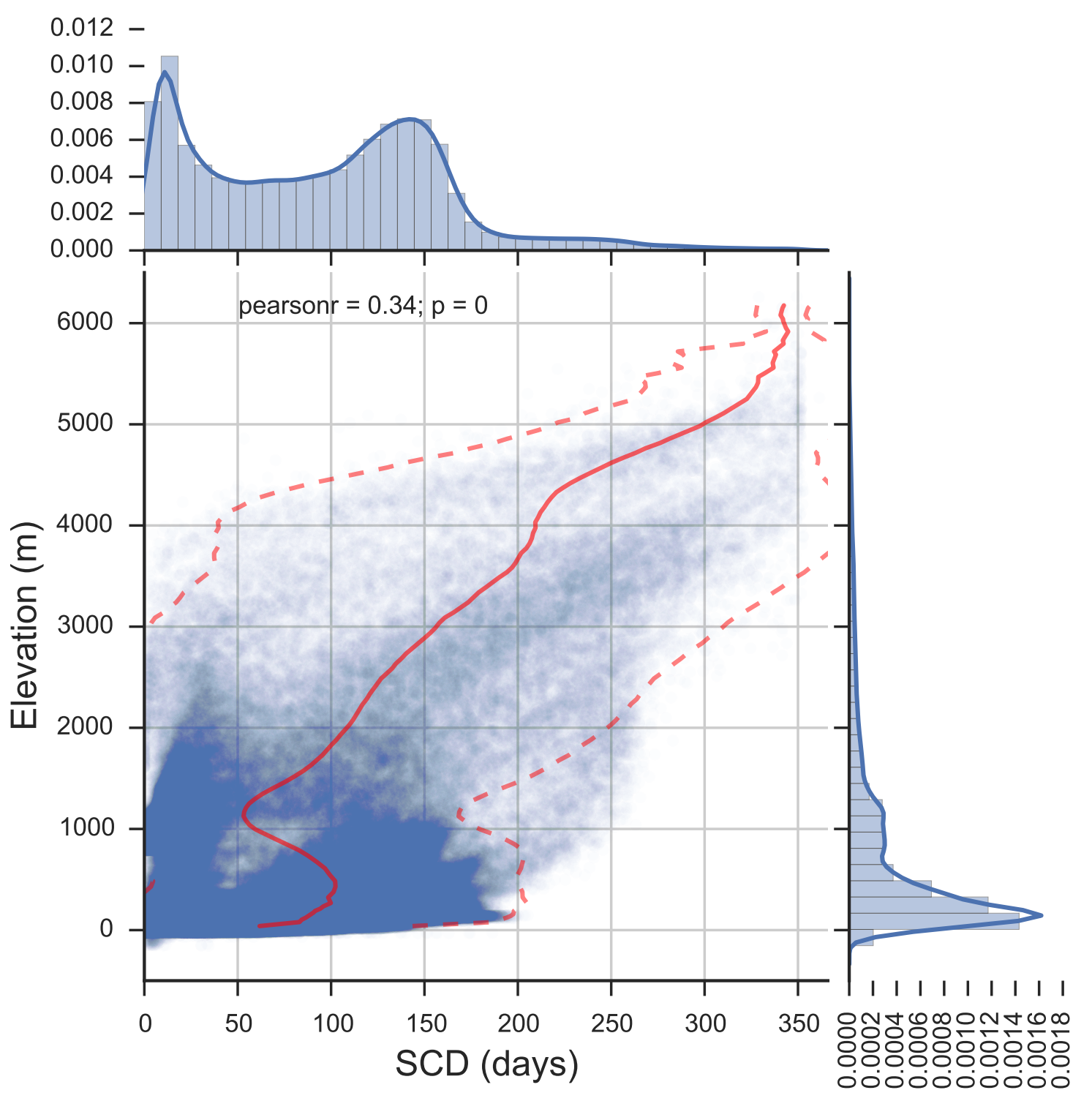


1) Kazakh Steppe
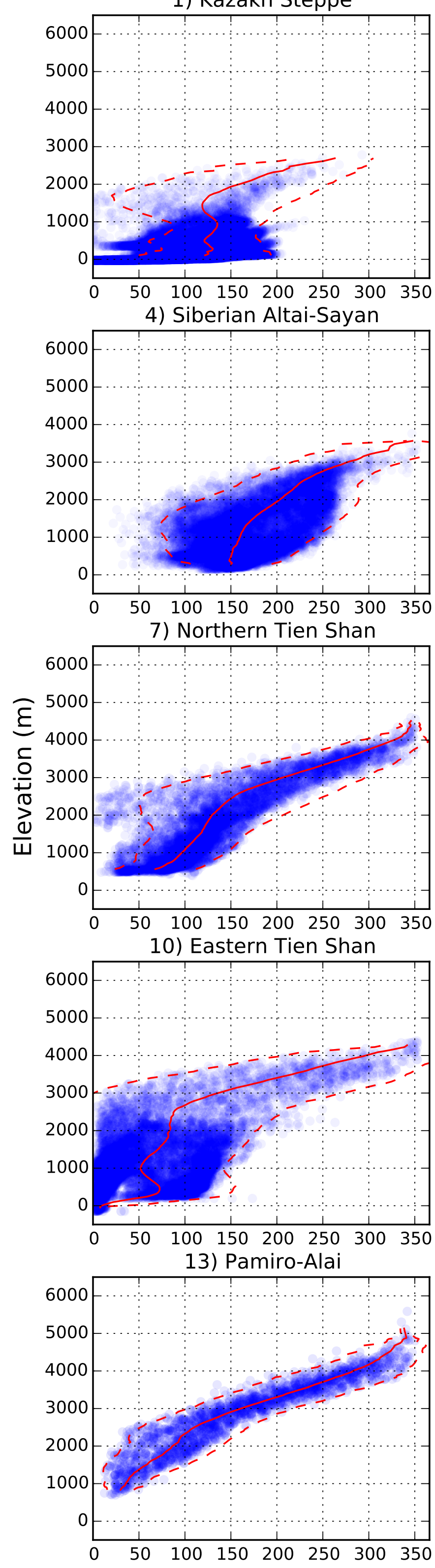

2) Aral-Caspian Deserts
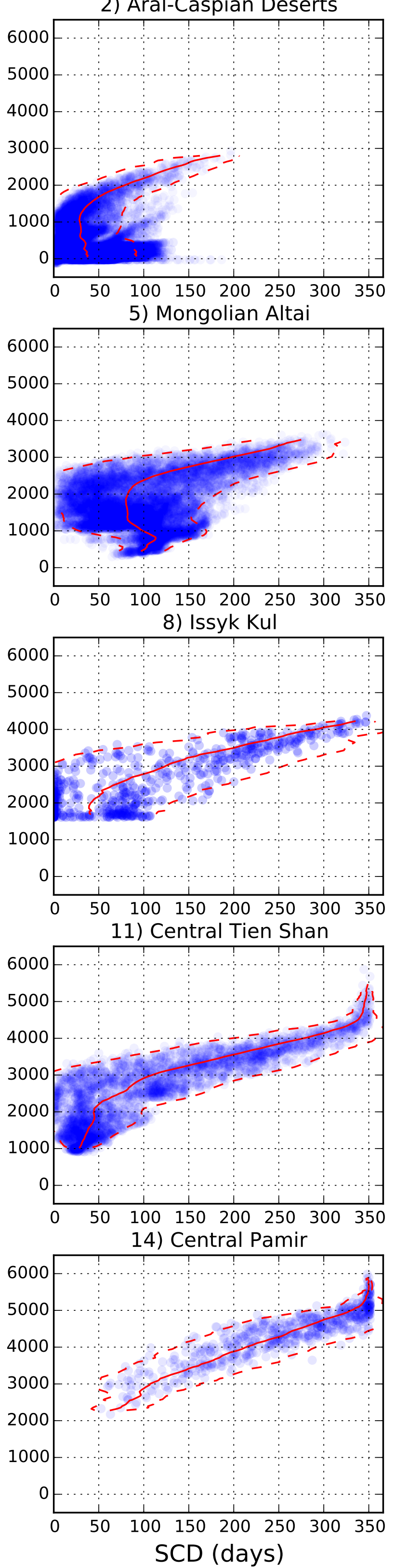

3) Tarim
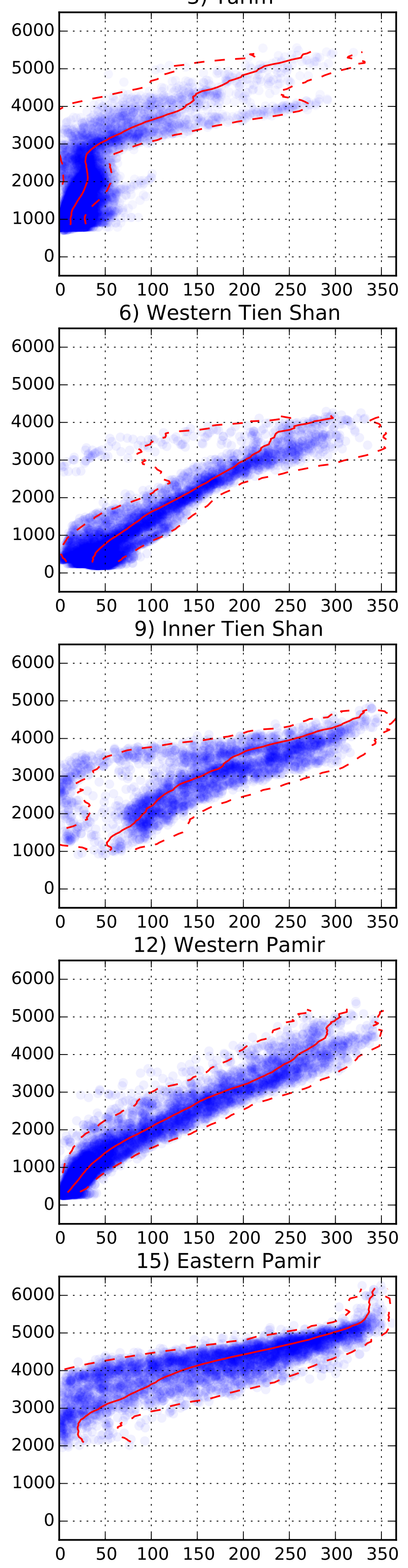


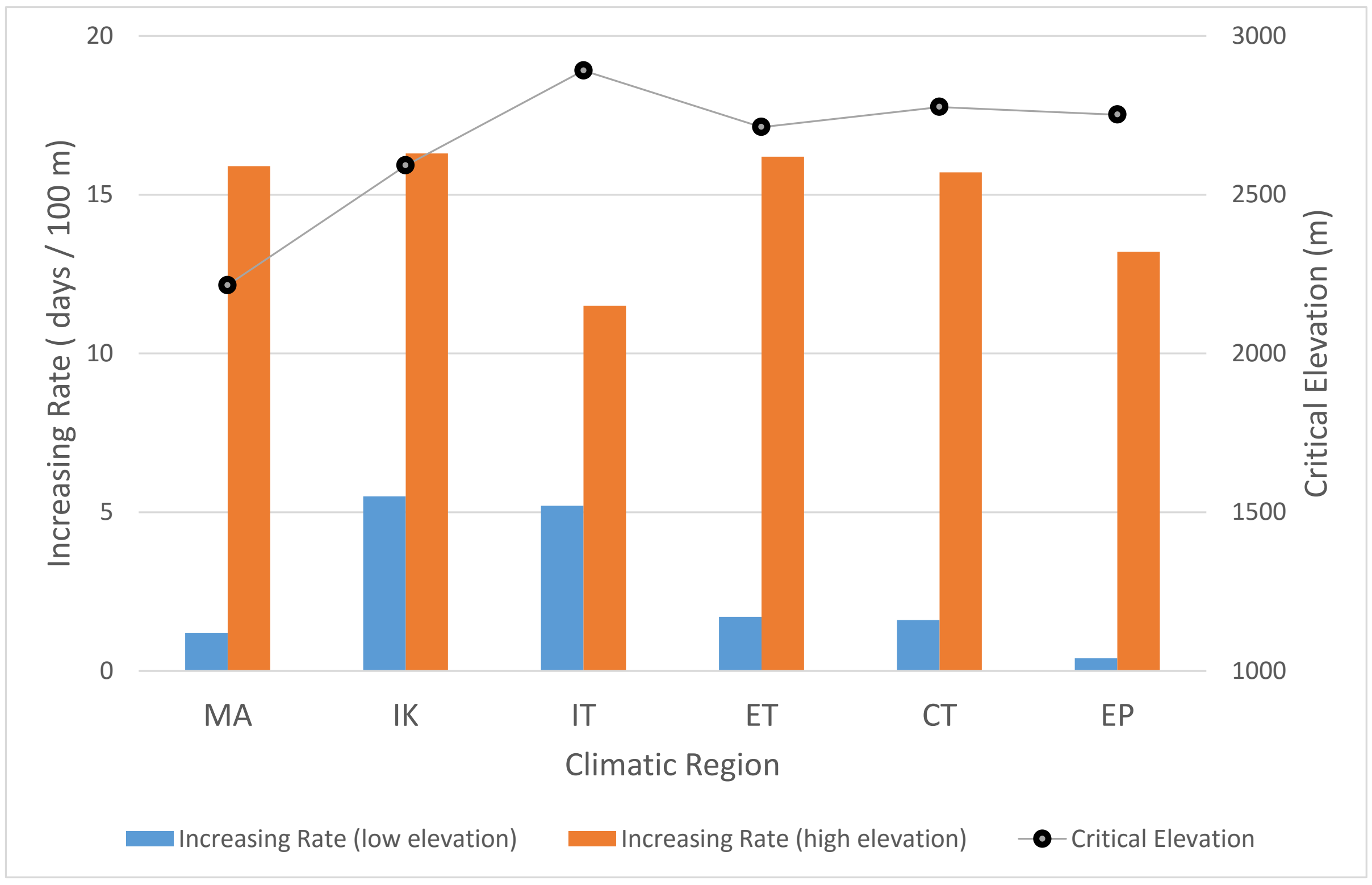




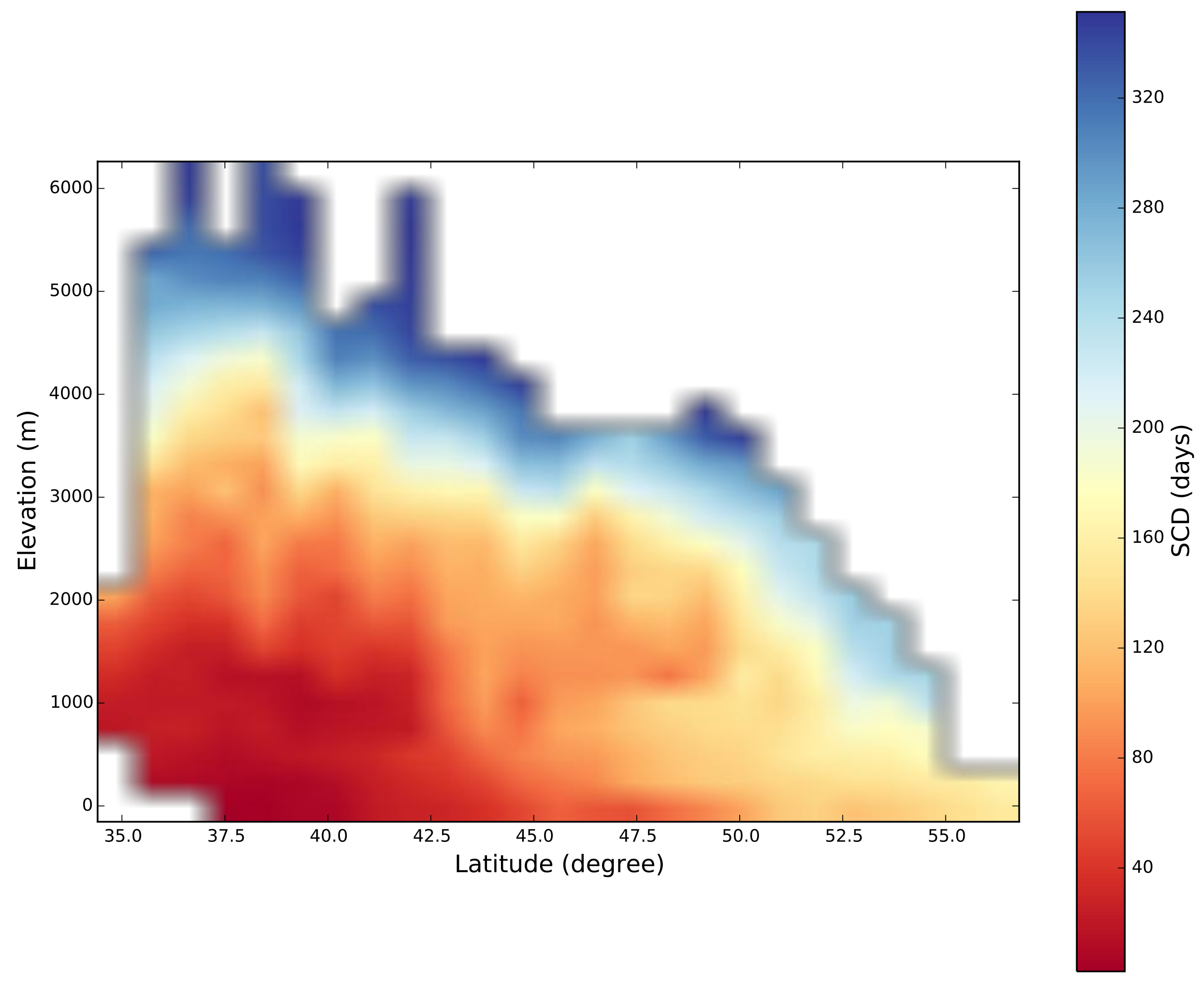



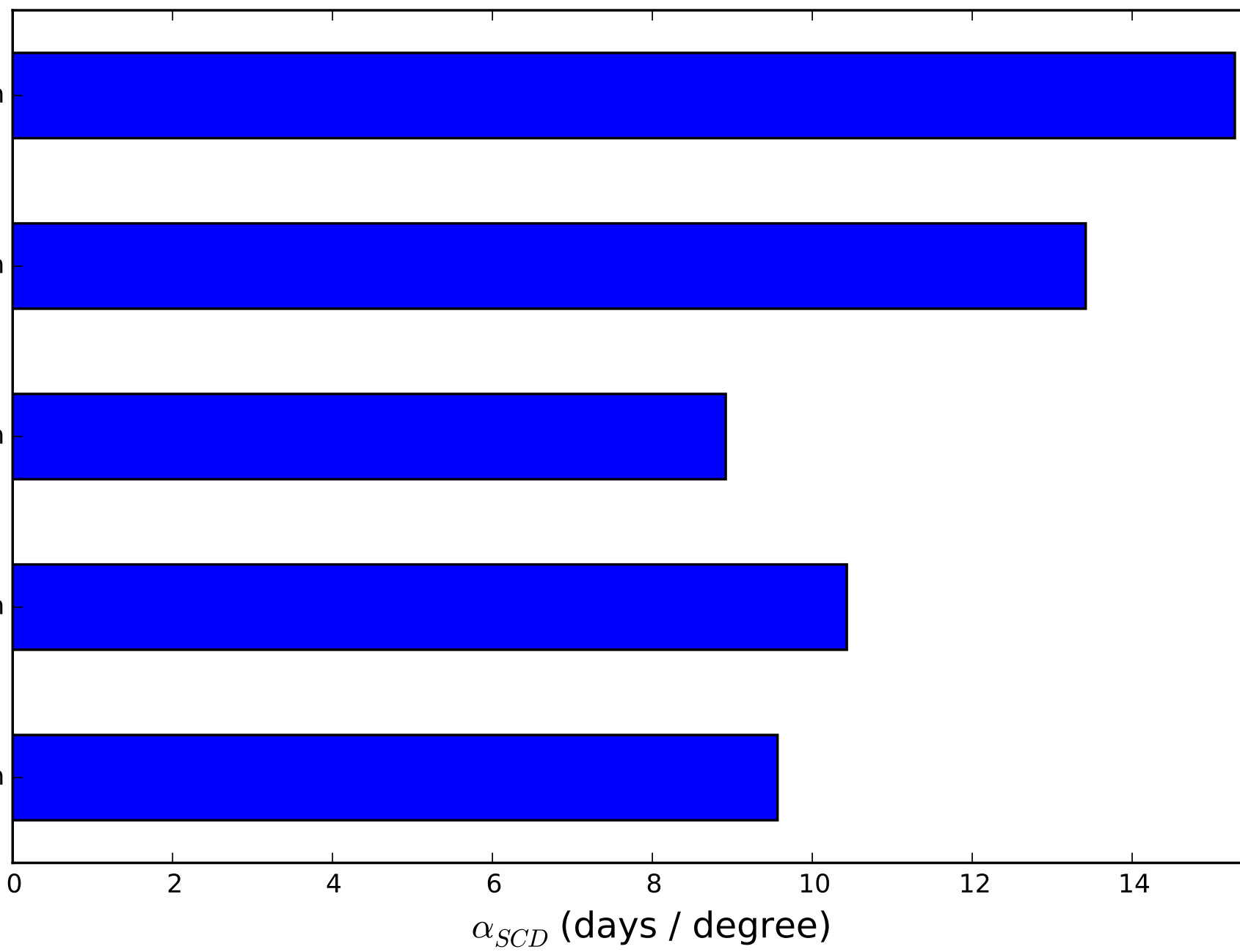


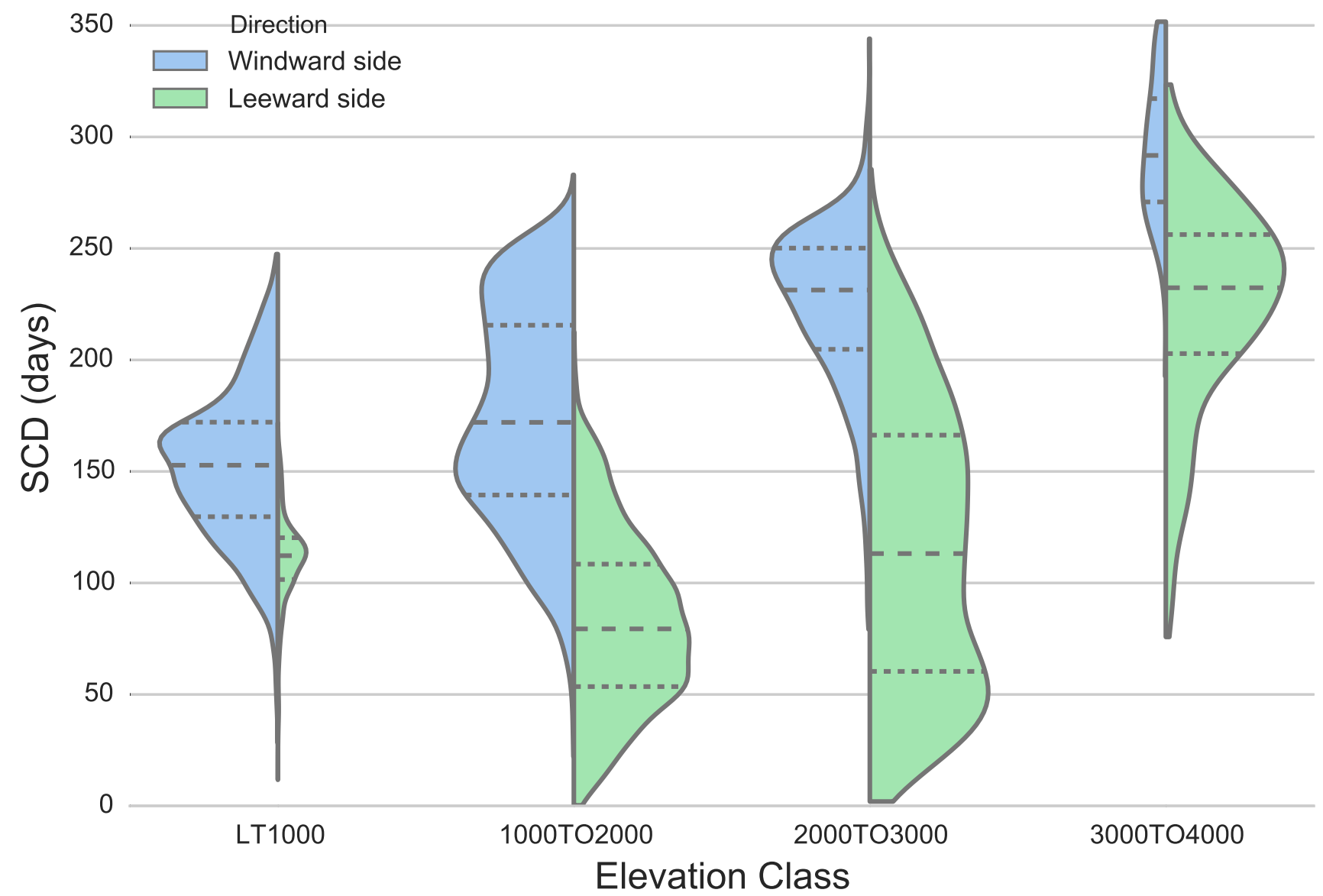




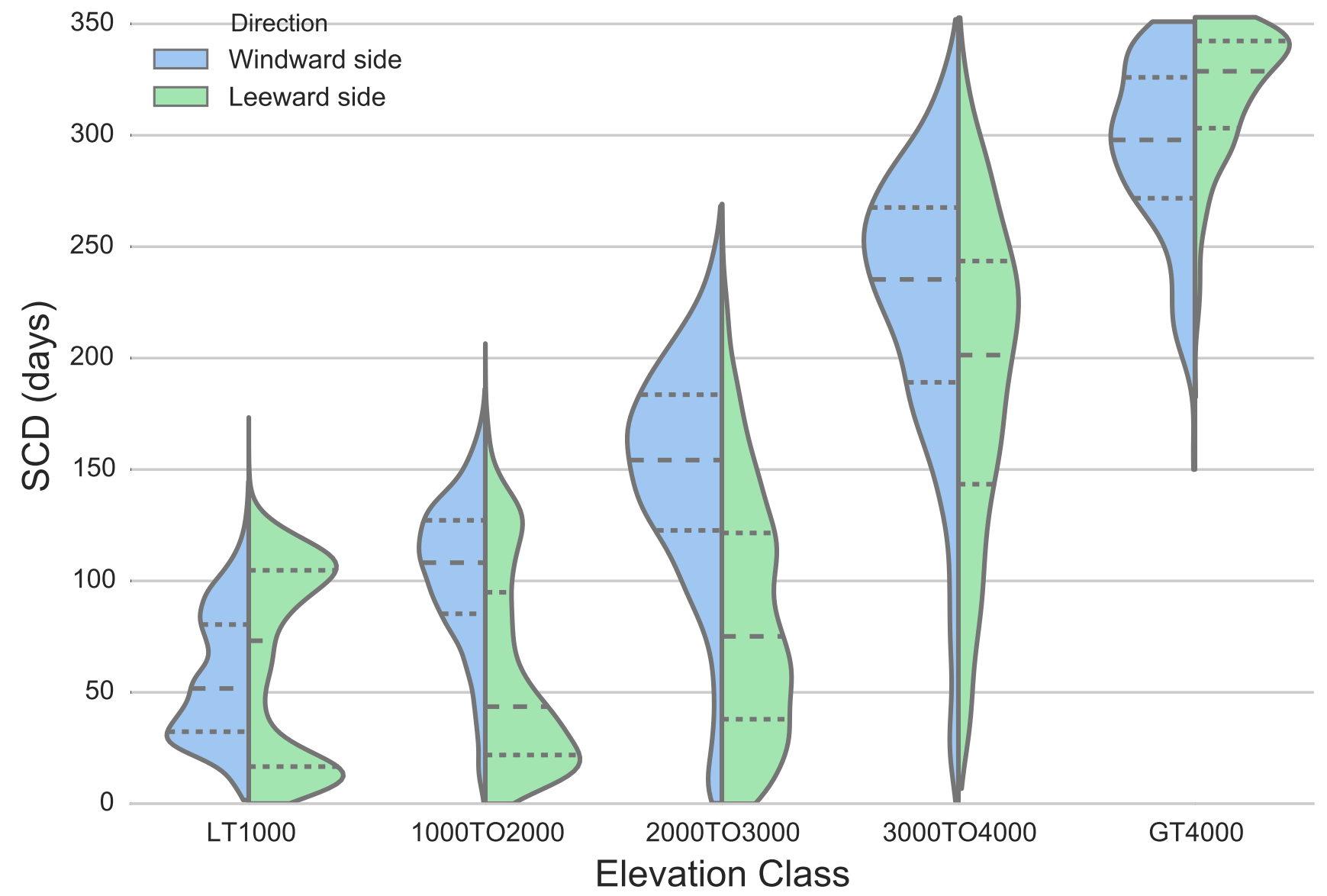




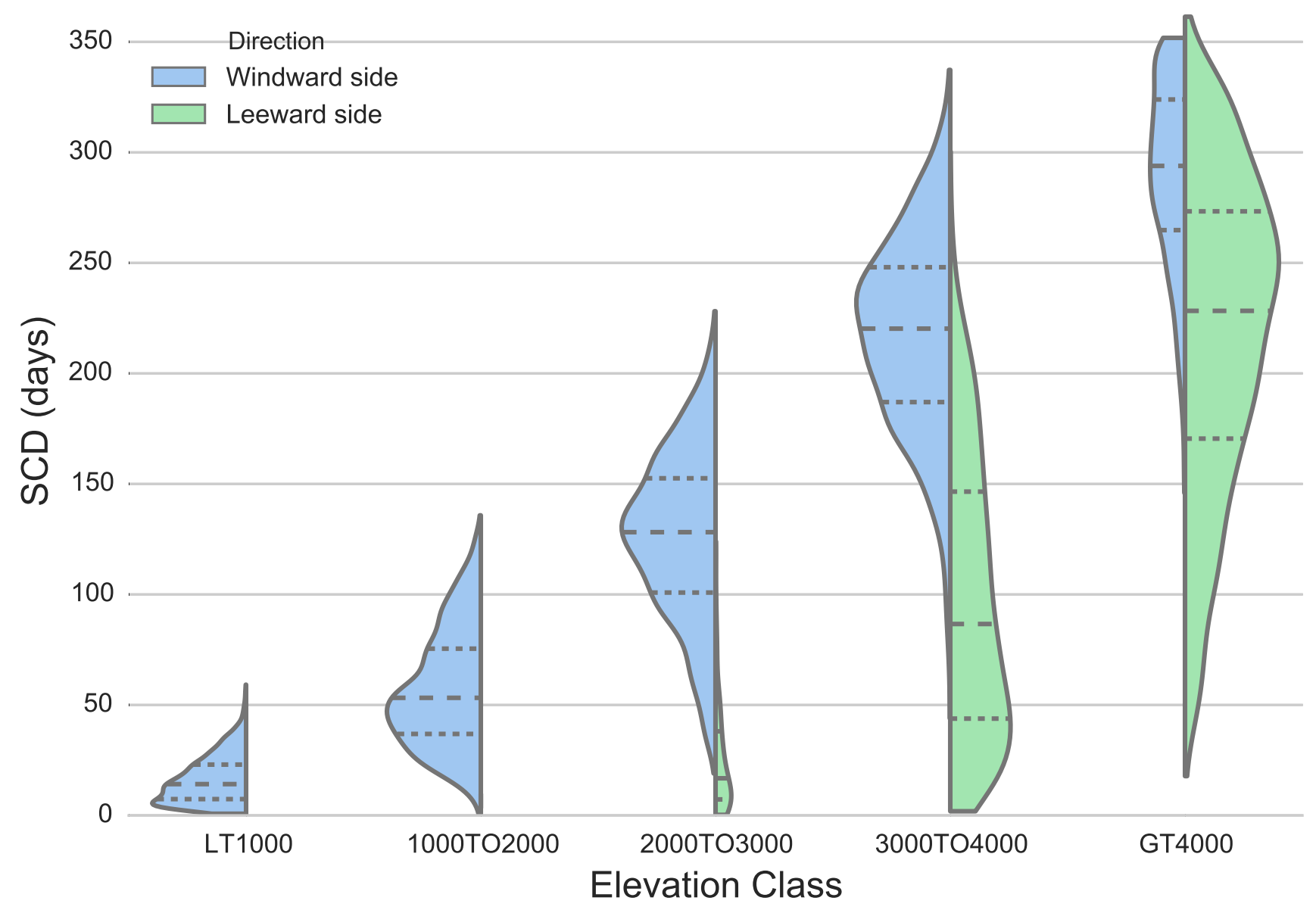




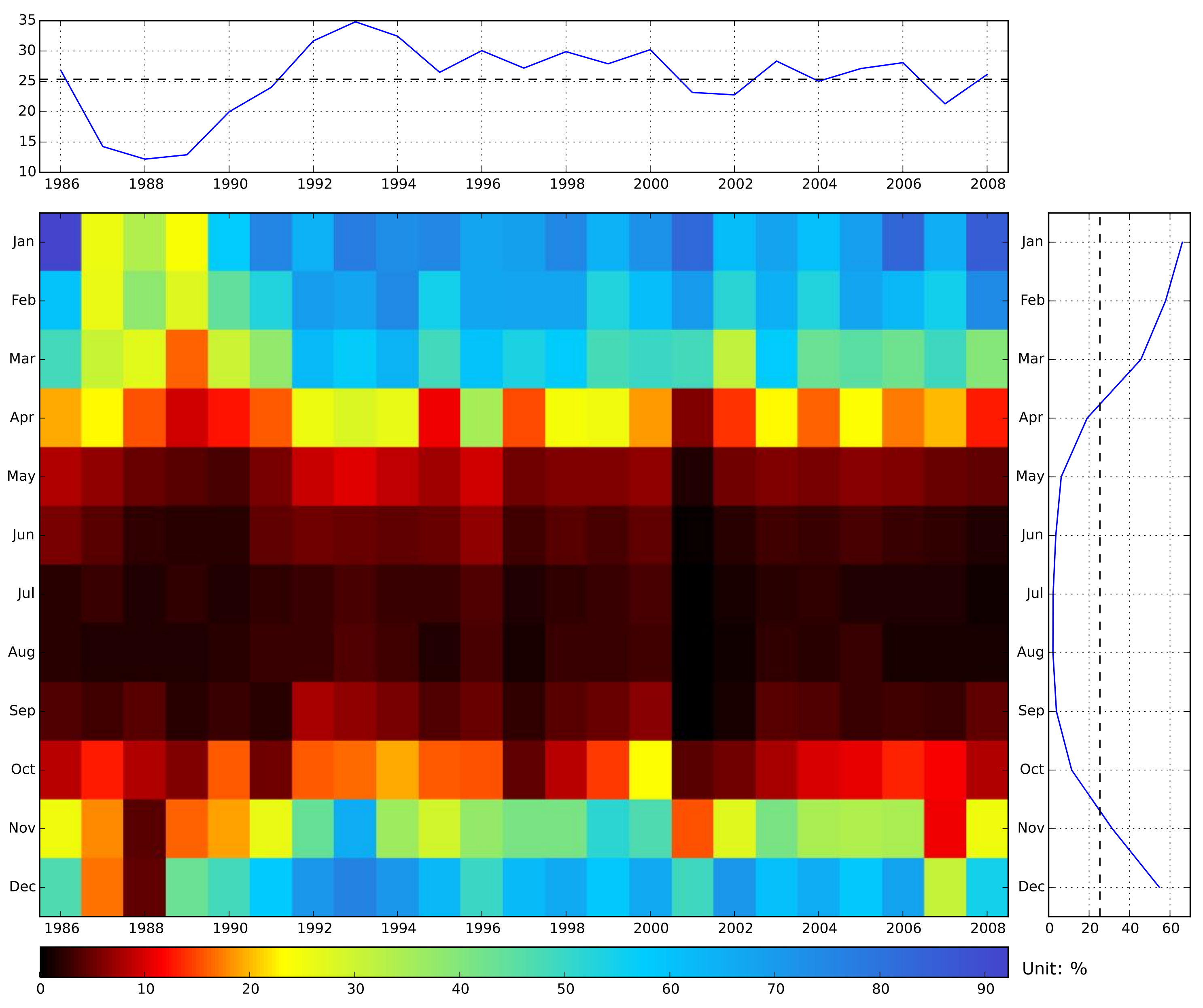

